\title{
Electrochemical behavior of copper species in the 1-buthyl-3-methyl-imidazolium chloride (BMIMCl) ionic liquid on a Pt electrode
}

\author{
E. Barrado ${ }^{\text {a,* }}$, J.A. Rodriguez ${ }^{\text {b }}$, P. Hernández ${ }^{\text {a }}$, Y. Castrillejo ${ }^{\text {a }}$ \\ a UIC.090, Dpto. de Química Analítica, F. de Ciencias, Universidad de Valladolid, Paseo de Belén 7, 47011, Valladolid, Spain \\ b Centro de Investigaciones Químicas, Universidad Autónoma del Estado de Hidalgo. Carr. Pachuca-Tulancingo Km. 4.5, C.P. 42076. Pachuca, Hidalgo, Mexico
}

\section{A R T I C L E I N F O}

\section{Article history:}

Received 20 October 2015

Received in revised form 28 January 2016

Accepted 22 February 2016

Available online 23 February 2016

\section{Keywords:}

Copper

Ionic liquids

Diffusion coefficient

Kinetic parameters

Nucleation

\begin{abstract}
A B S T R A C T
The electrochemical behavior of $\mathrm{Cu}(\mathrm{I})$ and $\mathrm{Cu}(\mathrm{II})$ species in the ionic liquid 1-buthyl-3-methylimidazolium chloride, $\mathrm{BMIMCl}$, on a platinum electrode in the interval of 333-363 K, has been investigated. Experiments performed in a controlled $\mathrm{N}_{2}$ atmosphere cell show that: (i) $\mathrm{Cu}$ (I) can be oxidized to $\mathrm{Cu}$ (II) and reduced to $\mathrm{Cu}(0)$, and (ii) $\mathrm{Cu}$ (II) can be reduced to $\mathrm{Cu}$ (I) by copper metal according to a comproportionation reaction whose constant has been calculated.

The diffusion coefficients of $\mathrm{Cu}(\mathrm{I})$ and $\mathrm{Cu}(\mathrm{II})$ have been obtained by different electrochemical techniques. The dimensionless Schmidt numbers ( $\mathrm{Sc}=v / \mathrm{D}$ ) were also calculated to characterize the solute global mass transport through its environment. The kinetic parameters for the quasi-reversible electrochemical exchange $\mathrm{Cu}(\mathrm{II})$ / $\mathrm{Cu}(\mathrm{I})$ (i.e. the intrinsic rate constant of charge transfer, $\mathrm{k}^{0}$, and the charge transfer coefficient, $\alpha$ ), as well as the reversible half wave potential, $\mathrm{E}_{1 / 2}^{\mathrm{r}}$, have been obtained for the first time in the mentioned ionic liquid, by simulation of the cyclic voltammograms and logarithmic analysis of the convoluted curves.

The apparent standard potential of the electrochemical system $\mathrm{Cu}(\mathrm{I}) / \mathrm{Cu}(0)$ has been determined by potentiometry. Founding that nucleation and crystal growth plays an important role in the electrodeposition of metallic Cu onto the Pt surface. Experimental current-time transients followed the theoretical models based on instantaneous nucleation with three-dimensional growth of the nuclei at the studied temperatures. Electrodeposits of copper were obtained by potentiostatic electrolysis and analyzed by scanning electron microscopy with EDAX.
\end{abstract}

(c) 2016 Elsevier B.V. All rights reserved.

\section{Introduction}

Ionic liquids (ILs) are commonly defined as compounds that are composed of cations and anions and melt at temperatures below $100{ }^{\circ} \mathrm{C}[1]$. They have been proposed as alternative solvents in electrodeposition processes due to: (i) their wide electrochemical window, which allow the deposition of high quality films including films of reactive metals, (ii) moderate ionic conductivity (no extra supporting electrolyte is required), (iii) low vapor pressure, (iv) significant thermal stability, (v) low toxicity and (vi) non flammability. As a result, electrodeposition in ILs can be a powerful tool for obtaining nanocrystalline materials without using any additive, being in most cases the less environmentally hazardous option.

Furthermore, ILs have found applications in various stages of nuclear fuel cycle: (i) as a substitute for n-dodecane in aqueous reprocessing, and (ii) as a possible alternative to high temperature molten salts in non-aqueous reprocessing [2,3]. To this end, various ILs having a wide electrochemical window, and adequate thermal and radiation stability

\footnotetext{
* Corresponding author.

E-mail address: ebarrado@qa.uva.es (E. Barrado).
}

has been proposed, being one of them the 1-butyl-3-methyl imidazolium chloride (BMIMCl) [3].

In order to realize and compare the possibilities offered by ILs versus molten salts in electrodeposition process and non-aqueous reprocessing, data on the physical and electrochemical properties of ILs, electrochemical properties of the elements, etc. must be accumulated. Taken into account that there are many challenges one must face with when using ILs, such as the high viscosity in comparison with conventional solvents and molten salts, as well as their complex structure leading to abnormal results in mass and charge-transfer dynamics. To this end, we have chosen the BMIMCl as media and copper as the transition element to be studied, and whose electrochemical behavior is well known in molten chlorides [4,5], due to the fact that copper is a base metal that nowadays is essential in the electronics industry [6,7] and can also be involved in electrochemical separation strategies by means of the formation of intermetallic compounds [8].

Copper plays a strategic role in electronics, particularly in printed circuit manufacture and specially for circuits interconnections in which copper has been replacing the historically dominant interconnect material aluminum, due to its lower resistivity that leads to decreased 
resistance-capacity delay $[9,10]$. The formation of a continuous and void-free $\mathrm{Cu}$ thin film is essential to the fabrication of $\mathrm{Cu}$ interconnects in microelectronics.

Several studies on copper electrochemistry in ionic liquids have been reported in the literature. $\mathrm{CuCl}$ is insoluble in 1-ethyl-3methylimidazolium tetrafluoroborate $\left(\mathrm{EMIM}-\mathrm{BF}_{4}\right)$ but becomes soluble when an excess of chloride ions, a complexing agent, is introduced to form the chloride rich ionic liquid (EMIM-Cl-BF $)$ [11], allowing the electrodeposition of $\mathrm{Cu}$ by the reduction of $\mathrm{Cu}(\mathrm{I})$ species. In this chloride rich media, the electrochemical system $\mathrm{Cu}(\mathrm{I}) / \mathrm{Cu}$ (II) exhibits a quasireversible charge transfer behavior, and the kinetic parameters have been provided by Chen et al. [12].

The solubility of copper salts in 1-butyl-1-methylpyrrolidinium bis(trifluoromethylsulfonyl)imide (BMP- $\mathrm{Tf}_{2} \mathrm{~N}$ ) based electrolytes is also limited. El Abedin et al. [13], managed to introduce $\mathrm{Cu}(\mathrm{I})$ ions in solution by anodic dissolution of copper, and deposited copper thin films with a nanocrystalline structure on gold substrates. The electrochemistry of $\mathrm{Cu}(\mathrm{I})$ and $\mathrm{Cu}(\mathrm{II})$ chloride complexes in the $\left(\mathrm{BMP}^{\mathrm{T}}-\mathrm{Tf}_{2} \mathrm{~N}\right)$ with different concentrations of chloride, (i.e. addition of 1-butyl-1methylpyrrolidinium chloride BMPCl), has been studied by Vainikka et al. [14]. The electrochemical system $\mathrm{Cu}(\mathrm{II}) / \mathrm{Cu}(\mathrm{I})$ has been found quasi-reversible, the diffusion coefficients and kinetic parameters of electron transfer being reported. The authors also pointed out: $i)$ the efficiency of the chemical reaction between $\mathrm{Cu}(\mathrm{II})$ and $\mathrm{Cu}(0)$ for preparing $\mathrm{Cu}(\mathrm{I})$ electrolytes, and ii) the existence of a three-coordinated complex $\mathrm{CuCl}_{3}^{2-}$ when the molar ratio $\left[\mathrm{Cl}^{-}\right] /[\mathrm{Cu}(\mathrm{I})]$ is higher than 4.7 , whereas there is also evidence of a second copper complex, $\mathrm{CuCl}_{2}^{-}$at smaller ratios. The formation of the three-coordinated complex, $\mathrm{CuCl}_{3}^{2-}$, has also been pointed out by Laher and Hussey [15] in the Lewis basic $\mathrm{AlCl}_{3}$-1-ethyl-3-methylimidazolium chloride at temperatures higher than $313 \mathrm{~K}$.

This paper is concerned with the electrochemical behavior of $\mathrm{CuCl}_{\mathrm{p}}^{1-\mathrm{p}}$ and $\mathrm{CuCl}_{\mathrm{m}}^{2-\mathrm{m}}$ - hereafter denoted as $\mathrm{Cu}(\mathrm{I})$ and $\mathrm{Cu}(\mathrm{II})$ - in a chloride rich ionic liquid, $\mathrm{BMIMCl}$, on a Pt electrode in the interval of temperatures between 333 and $363 \mathrm{~K}$. The first part of the paper is devoted to the electrochemical system $\mathrm{Cu}(\mathrm{II}) / \mathrm{Cu}(\mathrm{I})$. In this way, the intrinsic rate constant of charge transfer, $\mathrm{k}^{0}$, the charge transfer coefficient, $\alpha$, the reversible half way potential, $\mathrm{E}_{1 / 2}^{\mathrm{r}}$, as well as the diffusion coefficients of both $\mathrm{Cu}(\mathrm{I})$ and $\mathrm{Cu}(\mathrm{II})$ have been calculated for the first time in the mentioned ionic liquid, being the obtained values compared with those reported in other media with similar viscosity. In the second part, the standard potential of the electrochemical system $\mathrm{Cu}(\mathrm{I})$ / $\mathrm{Cu}(0)$ has been determined, as well as the equilibrium constant of the comproportionation reaction between $\mathrm{Cu}(\mathrm{II})$ and $\mathrm{Cu}(0)$. In addition, results concerning the electrodeposition of copper thin films from a solution containing $\mathrm{Cu}(\mathrm{I})$ at three temperatures are reported.

\section{Experimental}

\subsection{General features}

Stock solutions of $\mathrm{Cu}(\mathrm{I})$ and $\mathrm{Cu}(\mathrm{II})$, were prepared and stored until their use inside a homemade glove box under a $\mathrm{N}_{2}$ gas atmosphere, by direct addition of anhydrous $\mathrm{CuCl}$ and $\mathrm{CuCl}_{2}$ (Alfa Aesar 99.999 and 99.995\% respectively) to the ionic liquid BMIMCl (Aldrich 95\%, Mm $174.67 \mathrm{~g} / \mathrm{mol}$, CAS: 79917-90-1).

A portion of the respective stock solution was transferred to the electrochemical conical cell. Once, outside the globe box, dry dinitrogen (Alphagaz $\mathrm{N}_{2}$ (1) purchased from Air Liquide) was bubbled through the solution to ensure the absence of oxygen and water. To calculate $\mathrm{Cu}$ (I) and $\mathrm{Cu}$ (II) concentrations in $\mathrm{mol} \cdot \mathrm{cm}^{-3}$, the variation of density $\left(\rho, \mathrm{g} \mathrm{cm}^{-3}\right)$ of the BMIMCl with temperature $(\mathrm{K})$ must be taken into account, according to the following equation $[16,17]$.

$\rho=1.2452-0.0005490 \mathrm{~T}$.

\subsection{Electrodes and instrumentation}

The electrochemical experiments were carried out under a $\mathrm{N}_{2}$ atmosphere, using an EG\&G PAR Model 273 A potentiostat/galvanostat controlled with the PAR EG\&G M270 4.6 software. The electrochemical data were analyzed with the Echem software PAR EG\&G Model 271, the Cool Kinetics Analysis software 1.00, and the Condecom 2000 CV System version 1.20 EG\&G Instrument. A multimeter Fluke 45 , was also used for potentiometric measurements.

A three electrode setup configuration electrochemical conical double wall cell, Metrohm 6.1415.150, was used connected to a TAMPSON TC3 thermostat to control the temperature. Pt wires ( $\phi=1 \mathrm{~mm}$, surface 0.133 and $0.165 \mathrm{~cm}^{2}$ ) were used as working electrodes, the counter electrode was always an Amel Pt type 10 8053019 , with an area of $0.64 \mathrm{~cm}^{2}$. Due to the difficulty in preparing and stabilizing well-defined references, the use of quasi-reference electrodes, QRE, is a common practice in electrochemical studies in ionic liquids [18]. The majority of reports that employ QRE in ILs are based on silver or platinum immersed directly into the IL system $[18,19]$. When a $\mathrm{Cu}(\mathrm{I})$ solution is used, either $\mathrm{Ag}$ or Pt wires can be used as a QRE. Notwithstanding, in order to prevent any chemical reaction between $\mathrm{Cu}(\mathrm{II})$ and $\mathrm{Ag}(0)$, only Pt wires must be used for the studies with $\mathrm{Cu}(\mathrm{II})$ solutions. Unless stated, all the potentials will be referred to a Pt (QRE).

Previous to its use, the Pt wires electrodes were manually polished using a felt cloth impregnated with $1 \mu \mathrm{m}$ alumina size suspension (Buehler), and with a diamond suspension (Struers) $1 \mu \mathrm{m}$ in diameter. Afterwards the electrodes were cleaned with acetone in an ultrasonic bath, then with distilled water and concentrated hot sulfuric acid, and finally with ultrapure water Milli-Q.

\section{Results and discussion}

\subsection{Qualitative characterization of the electrochemical systems of copper on a Pt electrode}

Fig. 1 depicts a representative example of the cyclic voltammograms obtained with a solution of $\mathrm{Cu}(\mathrm{I})\left(\mathrm{C}_{0}=2.35 \times 10^{-5} \mathrm{~mol} \mathrm{~cm}{ }^{-3}\right)$ on a Pt electrode, in which two well separated processes can be observed. In the potential region between ${ }^{-} 0.7$ and $^{-} 1.4 \mathrm{~V}$ (zone 1$), \mathrm{Cu}(\mathrm{I})$ is reduced trough a cathodic wave $A_{c}$, associated with a sharp anodic peak $A_{a}$, which can be attributed to the formation/dissolution of a new phase, presumably $\mathrm{Cu}$ metal. This hypothesis was confirmed by deposition of the metal under potentiostatic conditions. The EDX analysis showed that the deposit so obtained consisted of metallic copper.

Zone 2, shows another group of signals, the anodic wave $B_{a}$ associated with the cathodic wave $B_{c}$, with the expected shape for an electrochemical exchange in which the reduced and oxidized species are both soluble in solution, and consequently it could be assigned to the oxidation of $\mathrm{Cu}(\mathrm{I})$ (wave $\mathrm{B}_{\mathrm{a}}$ ) and the reduction of the electrogenerated $\mathrm{Cu}(\mathrm{II})$ (wave $\mathrm{B}_{\mathrm{c}}$ ). The number of electrons involved in this electrochemical step was determined by square wave voltammetry.

For a simple reversible reaction between species in solution, the net current-potential curve must be bell-shaped and symmetrical about the half wave potential, like those represented in Fig. 2 [20]. The width of the half-peak, $W_{1 / 2}$, depends on the number of electrons exchanged and on the temperature as follows [21]:

$\mathrm{W}_{1 / 2}=3.52 \frac{\mathrm{RT}}{\mathrm{nF}}$

The validity of Eq. (2) was verified by plotting the peak current vs. the square root of the frequency. A linear relationship was observed in the $1-50 \mathrm{~Hz}$ frequency range. According to Eq. (2) a value of $1.0 \pm 0.1$ 


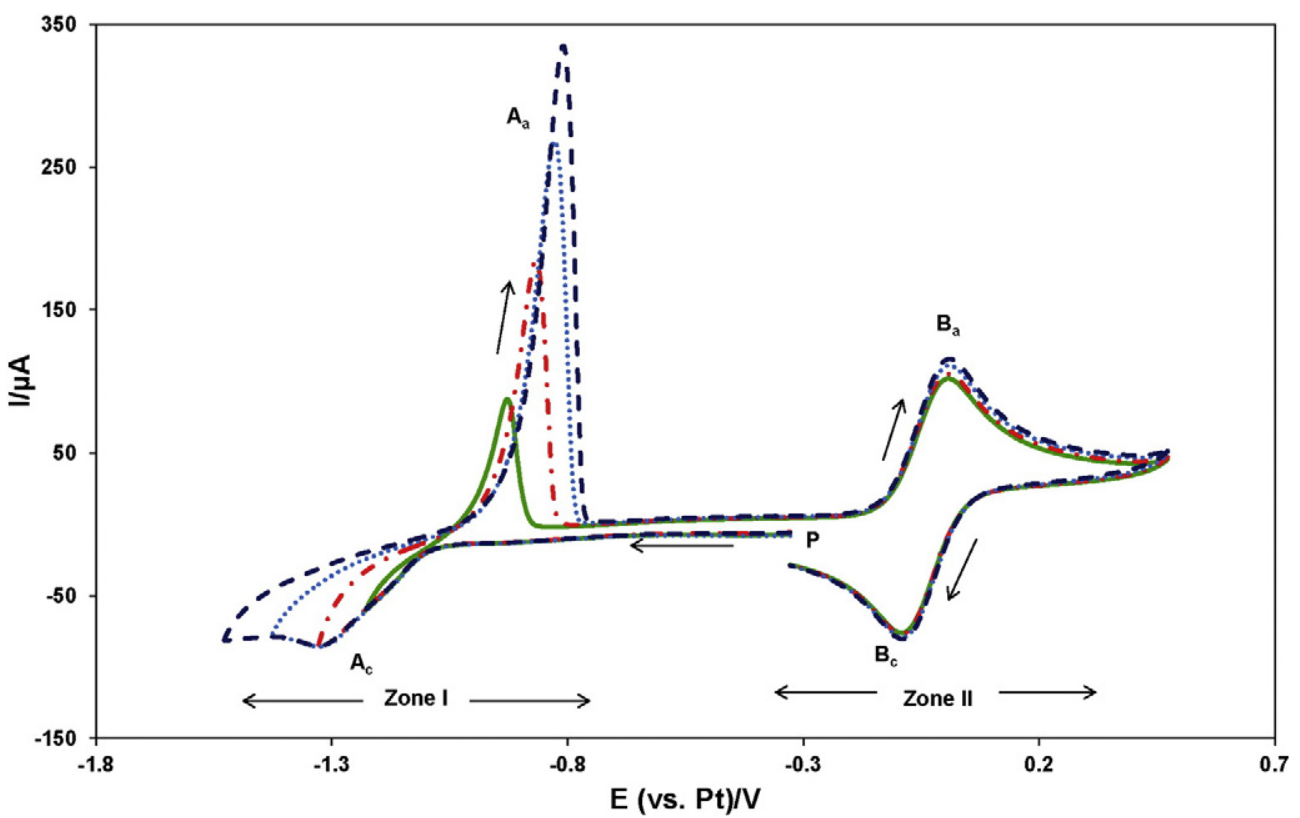

Fig. 1. Cyclic voltammogram obtained with a solution of $\mathrm{Cu}(\mathrm{I})$ in the $\mathrm{BMIMCl}$ ionic liquid on a Pt electrode $\left(\mathrm{C}_{0}=2.35 \times 10^{-5} \mathrm{~mol} \mathrm{~cm}^{-3}, \mathrm{~T}=363 \mathrm{~K}, \mathrm{sweep} \mathrm{rate} 50 \mathrm{mV} \mathrm{s}{ }^{-1}\right)$.

electrons was obtained, confirming that the waves $\mathrm{B}_{\mathrm{a}} / \mathrm{B}_{\mathrm{c}}$ correspond to the electrochemical exchange:

$\mathrm{Cu}(\mathrm{I})-1 \mathrm{e} \leftrightarrow \mathrm{Cu}(\mathrm{II})$

In this high chloride content media, the activity of Chloride, $\mathrm{a}_{\mathrm{Cl}-}$, is assumed to be $\mathrm{a}_{\mathrm{Cl}-}=1$; the very well separated one-electron stages showed in Fig. 1, pointed out the stabilization of $\mathrm{Cu}^{+}$by chloride complexation, with only one predominant chlorocomplex, $\mathrm{CuCl}_{\mathrm{p}}^{1-\mathrm{p}}$, probably $\mathrm{CuCl}_{3}^{2-}$, taken into account the results reported in other ILs with less $\mathrm{Cl}^{-}$ contents $[14,15]$. Hereafter the $\mathrm{CuCl}_{\mathrm{p}}^{1-\mathrm{p}}$ and $\mathrm{CuCl}_{\mathrm{m}}^{2-\mathrm{m}}$ chlorocomplexes will be denoted as $\mathrm{Cu}(\mathrm{I})$ and $\mathrm{Cu}(\mathrm{II})$ respectively.

\subsection{Electrochemical system $\mathrm{Cu}(\mathrm{II}) / \mathrm{Cu}(\mathrm{I})$}

The main purposes of this section are: i) to investigate the applicability of various transient electrochemical techniques for the determination of diffusion coefficients, ii) to take into account the solvent contribution through its viscosity to the solute transport, and iii) to determine the kinetic parameters relative to the electrochemical system.

3.2.1. Determination of the $\mathrm{Cu}(\mathrm{I})$ and $\mathrm{Cu}(\mathrm{II})$ diffusion coefficient. Verification of Arrhenius's law

3.2.1.1. Results obtained by cyclic voltammetry. A detailed investigation of the electrochemical system $\mathrm{Cu}(\mathrm{II}) / \mathrm{Cu}(\mathrm{I})$ was performed. Series of

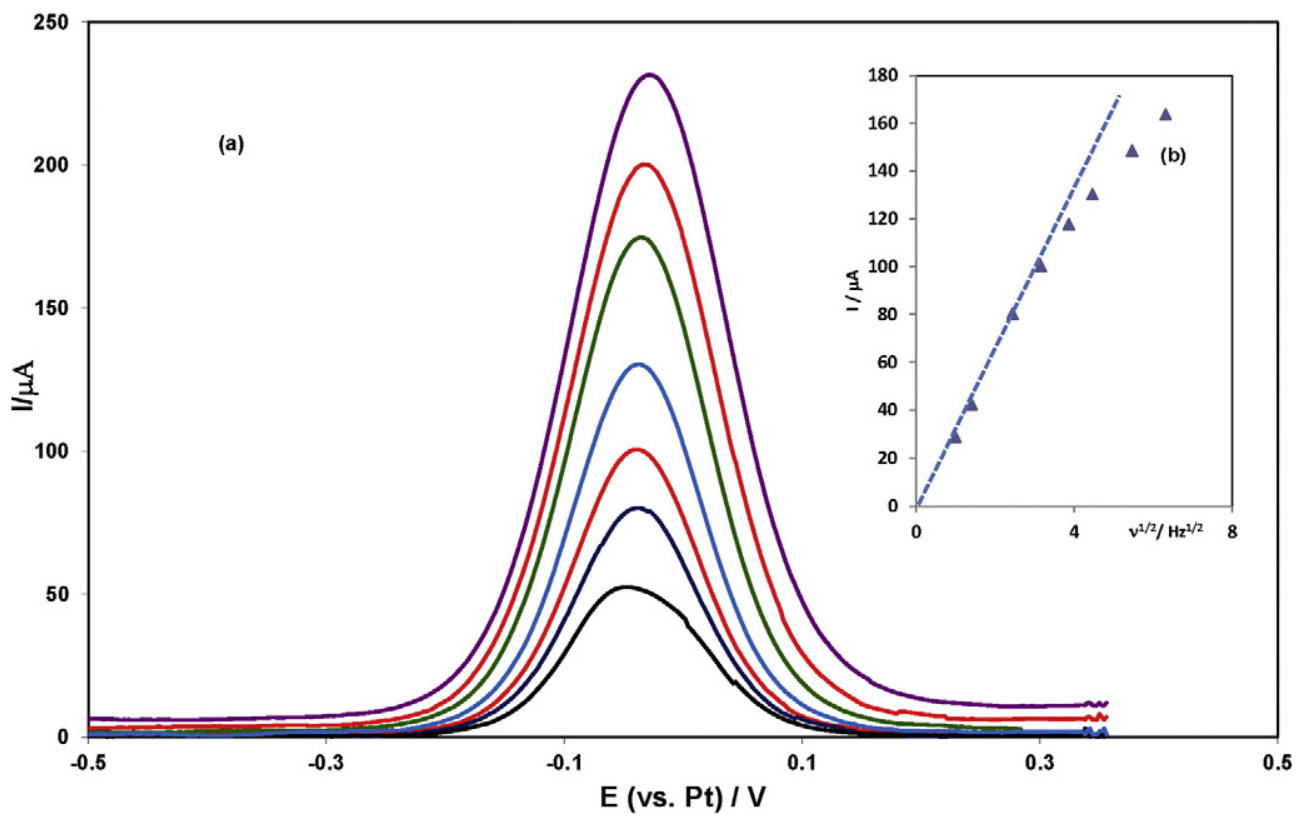

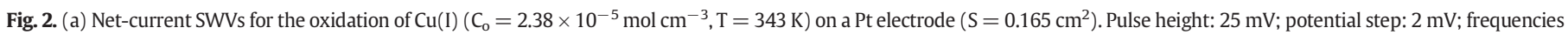
ranging from 2 to $200 \mathrm{~Hz}$. (b) Variation of the current with square of the frequency. 
voltammograms were recorded in the $\mathrm{BMIMCl}$ ionic liquid containing either $\mathrm{Cu}(\mathrm{II})$ or $\mathrm{Cu}(\mathrm{I})$ chlorocomplexes, for a variety of scan rates on a Pt wire electrode and at the selected temperatures (after compensation of the solution resistance which was determined by the positive feedback technique) (Figs. 3a and 4a). In all cases, plots of the cathodic and anodic peak currents versus the square root of the scan rate were found to be linear for potential scan rates ranging from 10 to $800 \mathrm{mV} \mathrm{s}^{-1}$ (Figs. 3b and $4 \mathrm{~b}$ ), while the peak potentials do not depend on the scan rate up to $200 \mathrm{mV} \mathrm{s}^{-1}$ (Figs. 3c and 4c). According to the theory of linear sweep voltammetry $[20,22,23]$, up to a sweep rate of $150 \mathrm{mV} \mathrm{s}^{-1}$ the electron process is controlled by the rate of mass transfer, whereas for higher scan rates, the electron transfer rate is significantly lower than that of the mass transport.

Despite the expected quasi-reversibility of the electrochemical system, the diffusion coefficients of $\mathrm{Cu}(\mathrm{II})$ and $\mathrm{Cu}(\mathrm{I})$, could be determined at the working temperatures from the voltammograms obtained at sweep rates up to $0.150 \mathrm{~V} \mathrm{~s}^{-1}$, (i.e. sweep rates at which the electron transfer is reversible on the timescale of the experiment), making it possible to use the Randles-Sevcik equation.

$\mathrm{I}_{\mathrm{p}}=0.4463(\mathrm{nF})^{3 / 2} \mathrm{SC}_{0} \mathrm{D}^{1 / 2} \mathrm{v}^{1 / 2}(\mathrm{RT})^{-1 / 2}$

where $\mathrm{C}_{0}$, D and $\mathrm{S}$, are the concentration $\left(\mathrm{mol} \mathrm{cm}^{-3}\right)$, diffusion coefficient of electroactive species $\left(\mathrm{cm}^{2} \mathrm{~s}^{-1}\right)$ and the electroactive area of the electrode $\left(\mathrm{cm}^{2}\right)$ respectively.

It has to be indicated that when a Pt wire was used as working electrodes, it is possible to use Eq. (4), which is relevant to plane semi-infinite diffusion, because under the experimental conditions, $\mathrm{v} \geq 10 \mathrm{mV} \mathrm{s}^{-1}$, the corrections related to cylindrical geometry can be neglected $[23,24]$.

The diffusion coefficient of $\mathrm{Cu}(\mathrm{I})$ and $\mathrm{Cu}(\mathrm{II})$ were calculated respectively from the slopes of the anodic and cathodic relationships, like those showed in Figs. 3 and 4. Mean values of the diffusion coefficients obtained at the studied temperatures are gathered in Table 1.

3.2.1.2. Results obtained by convolutive potential sweep voltammetry (CPSV). In the formulation of diagnostic criteria in the previous section, only the peak current and potential values have been used, ignoring the information contained in the rest of the wave. In order to overcome this disadvantage, the convolution of the cyclic voltammograms has been carried out. The key aspect of the convolutive potential sweep voltammetry, also referred to as semi-integral electroanalysis [25,26], is the convoluted (semi-integrated) current $\mathrm{m}(\mathrm{t})$, where $\mathrm{i}(\mathrm{u})$ is the current from the voltammogram.

$\mathrm{m}(\mathrm{t})=\frac{1}{\pi^{1 / 2}} \int_{0}^{\mathrm{t}} \frac{\mathrm{i}(\mathrm{u})}{(\mathrm{t}-\mathrm{u})^{1 / 2}} \mathrm{du}$

$\mathrm{m}(\mathrm{t})$ reaches a limiting value, $\mathrm{m}^{*}$, described by:

$\mathrm{m}^{*}=\mathrm{nFSC}_{0} \mathrm{D}^{1 / 2}$

at potential values sufficiently anodic or cathodic to ensure zero surface concentration and complete concentration polarization of the reactant.

Fig. 5 depicts examples of the cyclic voltammograms obtained with a solution of $\mathrm{Cu}(\mathrm{II})$, and their corresponding semi-integral curves. It can be observed that the direct and reverse scans are not identical and that hysteresis behavior occurs between the up and down sweeps being more important for higher scan rates, supporting the fact that the electrochemical system $\mathrm{Cu}(\mathrm{II}) / \mathrm{Cu}(\mathrm{I})$ is not fully reversible. On the other hand, the convoluted curves of the voltammograms exhibited well defined limiting currents, which values are independent of the scan rate. Therefore, the $\mathrm{Cu}(\mathrm{I})$ and $\mathrm{Cu}(\mathrm{II})$ diffusion coefficients could be computed from their respective boundary semi-integral values by means of Eq. (6) $[20,22,26]$. The obtained results are gathered in Table 1.

3.2.1.3. Results obtained by chronopotentiometry. The diffusion coefficients were also determined by chronopotentiometry, by means of the Sand's equation $[20,22,23,26]$

$\mathrm{I} \tau^{1 / 2}=\frac{\mathrm{nFSC}_{0} \mathrm{D}^{1 / 2} \pi^{1 / 2}}{2}$

where $\tau$ is the transition time measured in the chronopotentiograms, and $\mathrm{C}_{0}$, D and $\mathrm{S}$ have the same meaning and units indicated previously.

Transition times for several applied currents, I, were measured when solution of $\mathrm{Cu}(\mathrm{I})$ or $\mathrm{Cu}(\mathrm{II})$ were employed, and the resultant $\mathrm{J}^{1 / 2} \mathrm{C}^{-1}$ versus J plots yielded to a constant value, indicating that the fluxes of

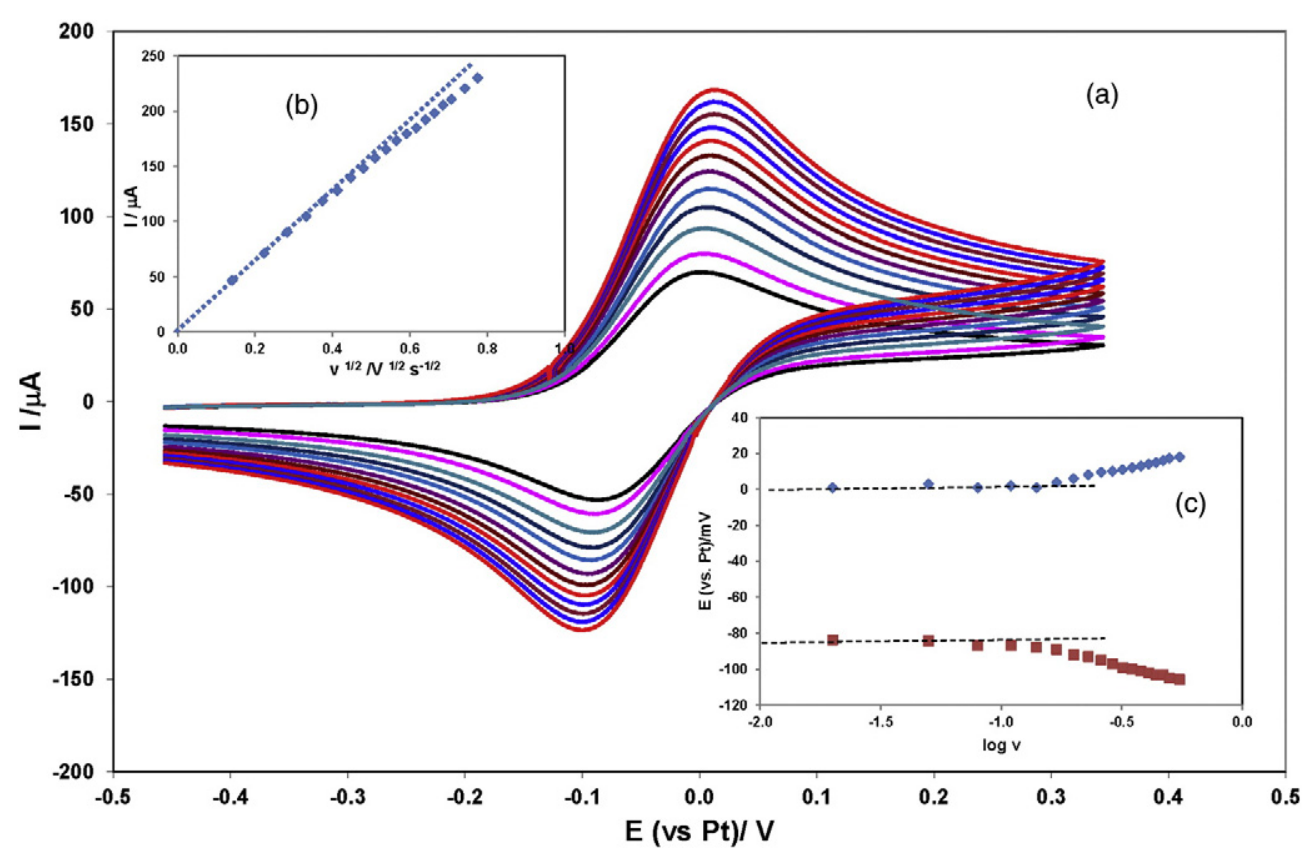

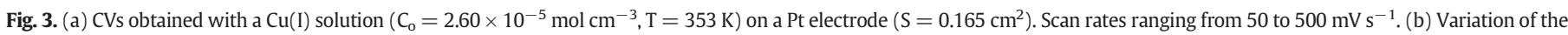
peak currents with the square root of the sweep rate. (c) Variation of the cathodic and anodic peak potentials with the logarithm of the sweep rate. 


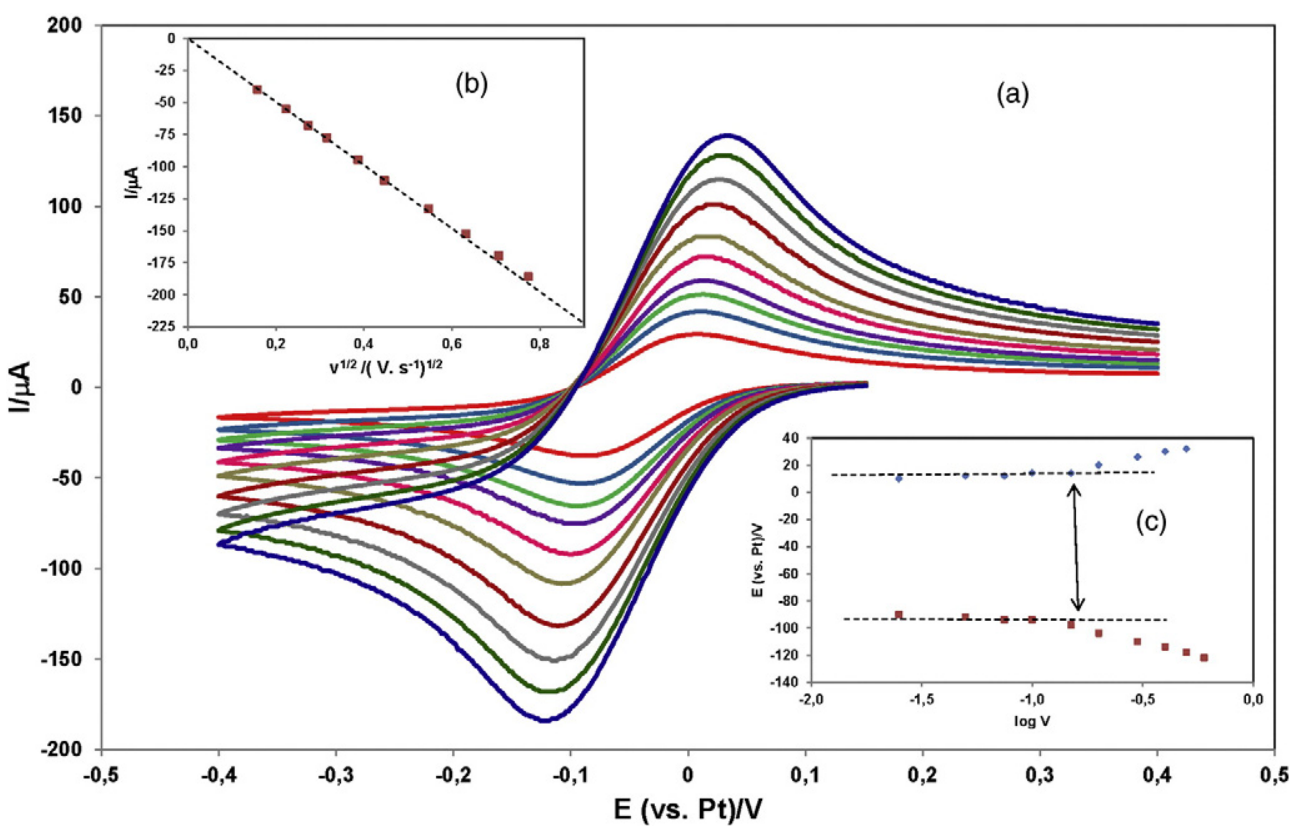

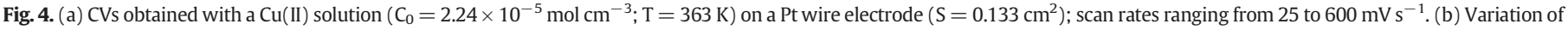
the cathodic and anodic peak current with the square root of the sweep rate. (c) Variation of the cathodic and anodic peak potential with the logarithm of the sweep rate.

the respective electroactive species was diffusion controlled and that all the requirements for using the Sand equation were fulfilled.

Fig. 6 shows examples of the chronopotentiograms obtained with a solution of $\mathrm{Cu}(\mathrm{I})$ on a Pt electrode at various imposed currents, when the concentration of $\mathrm{Cu}(\mathrm{I})$, the surface area of the working electrode and the temperature of the system were kept constant. The square root of the transition time changed linearly with the applied current, and the diffusion coefficients was calculated by Eq. (7).

3.2.1.4. Results obtained by chronoamperometry. A study of the electrochemical oxidation of $\mathrm{Cu}(\mathrm{I})$ and reduction of $\mathrm{Cu}(\mathrm{II})$ on the platinum electrode was also made using chronoamperometry. Fig. 7 shows examples of the chronoamperograms obtained with a solution of $\mathrm{Cu}(\mathrm{II})$ on the Pt electrode. By plotting the variation of the current vs $1 / t^{1 / 2}$ at the potentials at potential values in the mass-transfer controlled region, where the concentration of the electroactive species is nearly zero at the electrode surface, and the current is totally controlled by mass transfer (i.e. electrode kinetics no longer influence the current), it can be shown that the experimental data obey the Cottrell law $[20,22,23,26]$.

$I_{d}(t)=\frac{n F S D^{1 / 2} C_{0}}{\pi^{1 / 2} t^{1 / 2}}$
The diffusion coefficients were therefore calculated from the slopes of the respective straight lines.

Table 1 reports the values of the diffusion coefficients $\mathrm{D}_{\mathrm{Cu}(\mathrm{II})}$ and $\mathrm{D}_{\mathrm{Cu}(\mathrm{I})}$ obtained by using the above electrochemical techniques.

The solute transport results have to take into account the solvent contribution through its viscosity (i.e. a viscosity increase leads to a more difficult solute mass transport). Kinematic viscosities $\nu / \mathrm{m}^{2} \mathrm{~s}^{-1}$ defined as the ratio between dynamic viscosity $\eta / \mathrm{kg} \mathrm{m}^{-1} \mathrm{~s}^{-1}$ and density $\rho / \mathrm{kg} \mathrm{m}^{-3}$ were calculated from $[16,17]$ and gathered in Table 1 .

In order to take into account the effect of the viscosity on $\mathrm{Cu}$ (II) and $\mathrm{Cu}(\mathrm{I})$ diffusion coefficients, the dimensionless Schmidt number $(\mathrm{Sc}=$ v/D) was calculated to characterize the solute global mass transport through its environment. The calculated Sc numbers are also gathered in Table 1.

It has to be mentioned that the values of the diffusion coefficients obtained in this work are in good agreement with those reported for $\mathrm{Pd}(\mathrm{II})$ [27] and $\mathrm{U}(\mathrm{VI})$ [28] in the same ionic liquid, and also with those reported by Mandroyan et al. [29] for $\mathrm{Cu}(\mathrm{II})$ and $\mathrm{Cu}(\mathrm{I})$ in a Deep Eutectic Solvent (choline chloride-ethylene glycol) with a similar dynamic viscosity to BMIMCl (see Table 1 ).

In order to know if there are significant differences between: i) the calculated data at different temperatures, ii) the calculated data using different electrochemical techniques, and iii) the calculated data for

Table 1

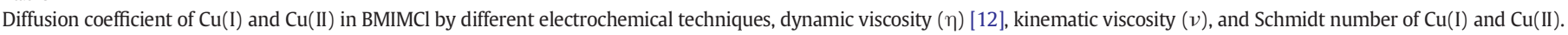

\begin{tabular}{|c|c|c|c|c|c|c|c|c|}
\hline \multicolumn{6}{|c|}{$\mathrm{DCu}(\mathrm{I}) / 10^{-8} \mathrm{~cm}^{2} \mathrm{~s}^{-1}$} & \multicolumn{3}{|c|}{$\mathrm{DCu}(\mathrm{II}) / 10^{-8} \mathrm{~cm}^{2} \mathrm{~s}^{-1}$} \\
\hline $\mathrm{T} / \mathrm{K}$ & 333 & 343 & 353 & 363 & & 343 & 363 & \\
\hline $\mathrm{CV}$ & $2.2 \pm 0.2$ & $4.0 \pm 0.3$ & $7.4 \pm 0.3$ & $13.3 \pm 0.3$ & & $2.8 \pm 0.2$ & $11.5 \pm 0.3$ & \\
\hline CPSV & $3.0 \pm 0.6$ & $4.3 \pm 0.4$ & $10.6 \pm 0.2$ & $16.0 \pm 0.4$ & & $3.7 \pm 0.1$ & $13.0 \pm 0.4$ & \\
\hline $\mathrm{CP}$ & $1.7 \pm 0.6$ & $3.5 \pm 0.3$ & $8.3 \pm 0.5$ & $10.3 \pm 0.4$ & & $2.5 \pm 0.2$ & $10.0 \pm 0.2$ & \\
\hline CA & $1.6 \pm 0.4$ & $3.2 \pm 0.3$ & $9.6 \pm 0.5$ & $12.2 \pm 0.5$ & & $3.6 \pm 0.3$ & $12.2 \pm 0.5$ & \\
\hline Mean value & $2.1 \pm 0.9$ & $3.8 \pm 0.7$ & $9.0 \pm 0.8$ & $13.6 \pm 0.8$ & $18.6^{\mathrm{a}}[29]$ & $3.6 \pm 0.4$ & $11.7 \pm 0.7$ & $22.8^{\mathrm{a}}[29]$ \\
\hline$\eta / \mathrm{mPa} s$ & $536.78[16]$ & $270.07[16]$ & $149.16[16]$ & $89.07[16]$ & $84.0[29]$ & $270.07[16]$ & $0.086[16]$ & 89.07 [29] \\
\hline$v / \mathrm{cm}^{2} \mathrm{~s}^{-1}$ & 5.05 & 2.55 & 1.42 & 0.85 & 0.79 [29] & 2.55 & 0.85 & 0.79 [29] \\
\hline $\mathrm{SC} / 10^{6}$ & 238 & 68.1 & 15.8 & 6.6 & 4.3 & 75.0 & 7.6 & 3.5 \\
\hline
\end{tabular}

a values reported by Mandroyan et al. in a deep eutectic solvent (choline chloride-ethylene glycol) at $273 \mathrm{~K}$ [29]. 


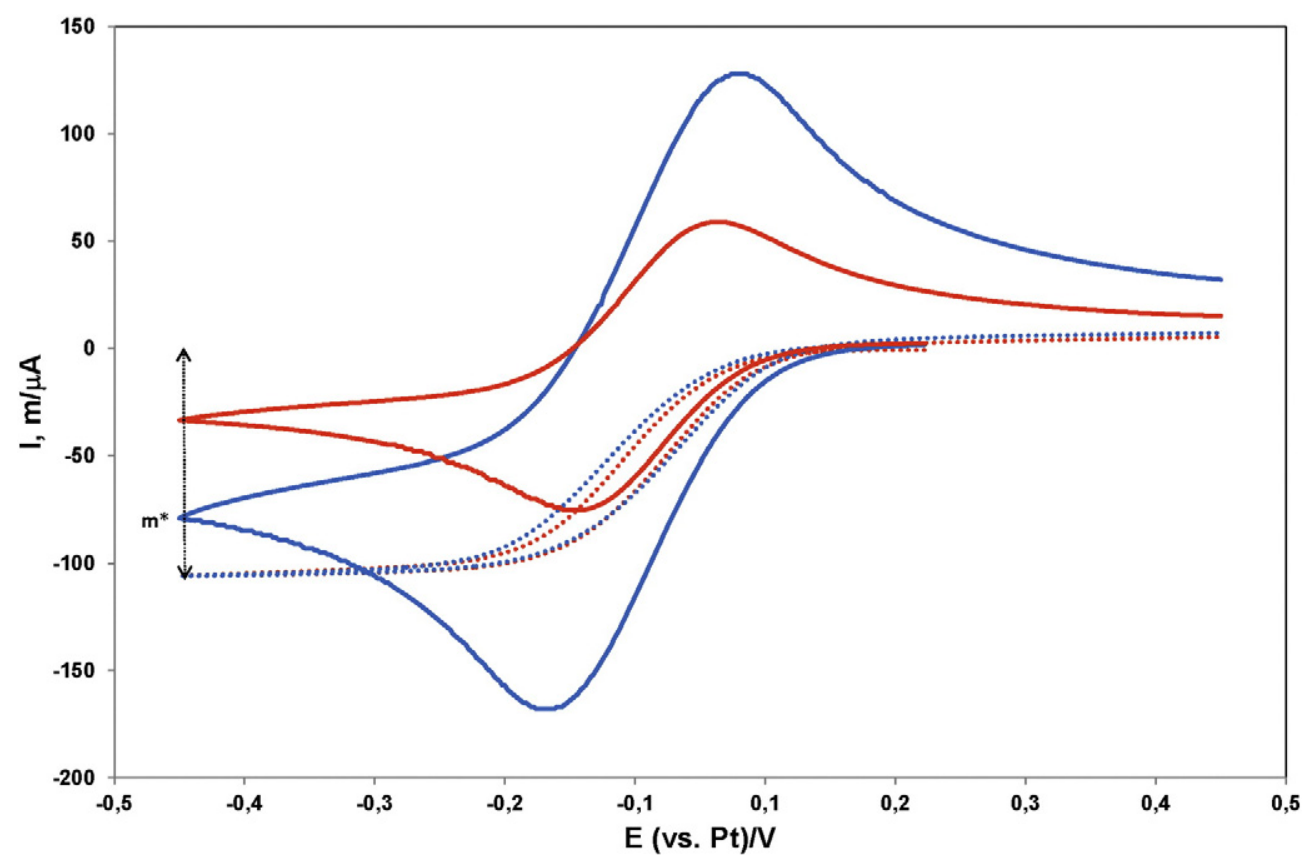

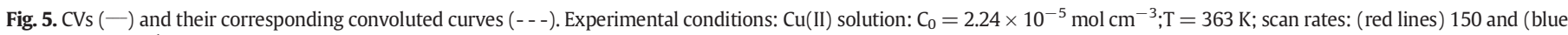
lines) $500 \mathrm{mV} \mathrm{s}^{-1}$. (For interpretation of the references to colour in this figure legend, the reader is referred to the web version of this article.)

$\mathrm{Cu}(\mathrm{I})$ and $\mathrm{Cu}(\mathrm{II})$, a statistical treatment, a two-way analysis of variance (ANOVA) [30] was carried out and the results are gathered on Table 2. The null hypothesis was the non-existence of significant differences between the calculated units. Concerning the temperature effect, the calculated F statistic was higher than the critical F value, therefore the null hypothesis must be rejected, whereas for the other effects, the calculated F statistics was lower than a critical F value, then the null hypothesis must be maintained, and it can be concluded that with a 95\% confidence level: i) the four methods used to calculate the diffusion coefficients lead to the same values, ii) there are no significant differences between the diffusion coefficients of $\mathrm{Cu}(\mathrm{I})$ and $\mathrm{Cu}(\mathrm{II})$ species, and iii) the diffusion coefficients change with temperature, following Arrhenius's law in the temperature range measured (Fig. 8):

$\log D=2.34( \pm 0.91)-\frac{3340( \pm 317)}{T}$

the activation energy for the diffusion was found to be $64 \pm 6 \mathrm{~kJ} / \mathrm{mol}$, a value in agreement with the previously reported for $\mathrm{Pd}(\mathrm{II})(63 \mathrm{~kJ} / \mathrm{mol})$ [27] and $\mathrm{Eu}(\mathrm{III})(62.6 \mathrm{~kJ} / \mathrm{mol})$ [31] in the same ionic liquid.

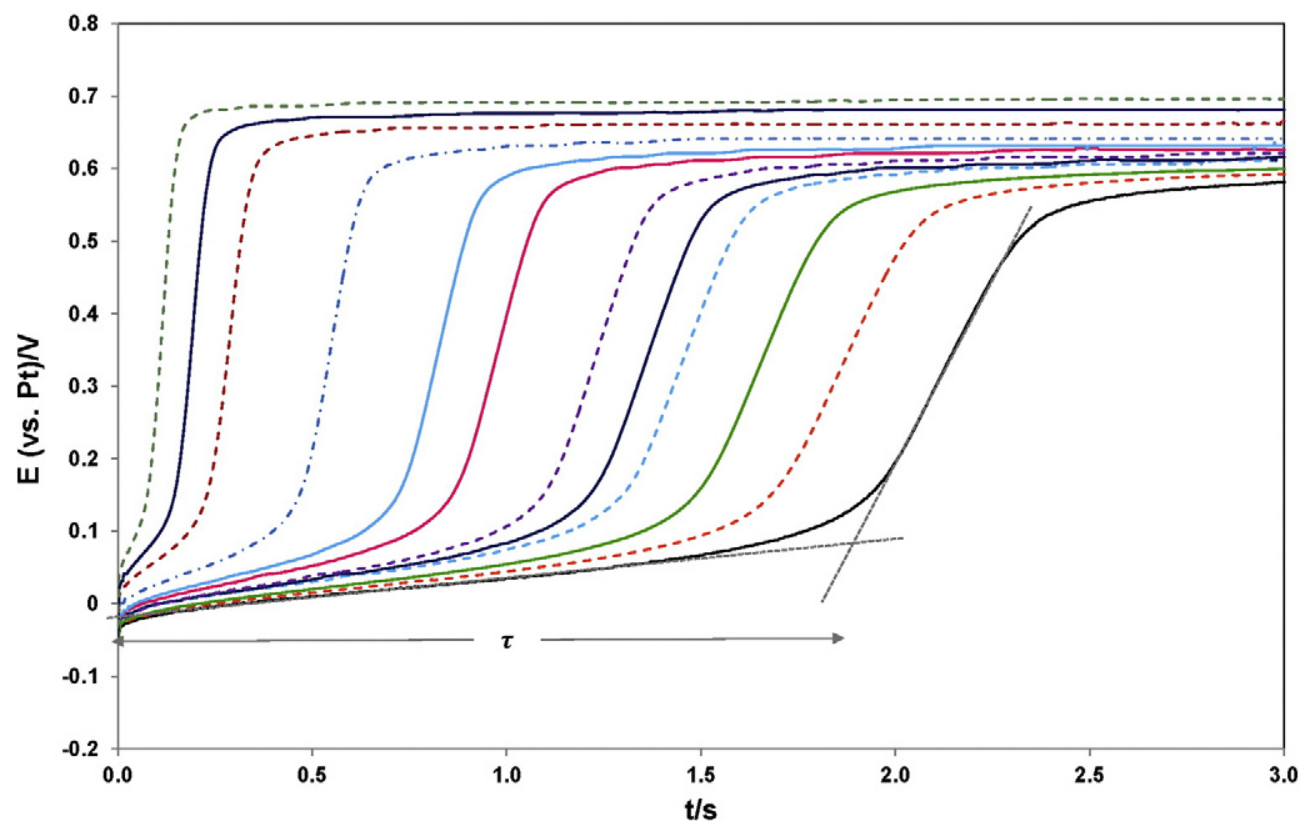

Fig. 6. (a) Chronopotentiograms obtained on a Pt electrode $\left(S=0.165 \mathrm{~cm}^{2}\right)$ with a $\mathrm{Cu}(\mathrm{I})$ solution, $\mathrm{C}_{0}=2.35 \times 10^{-5} \mathrm{~mol} \mathrm{~cm}^{-3}$ at various applied currents ranging from 80 to $300 \mu \mathrm{A}$. 


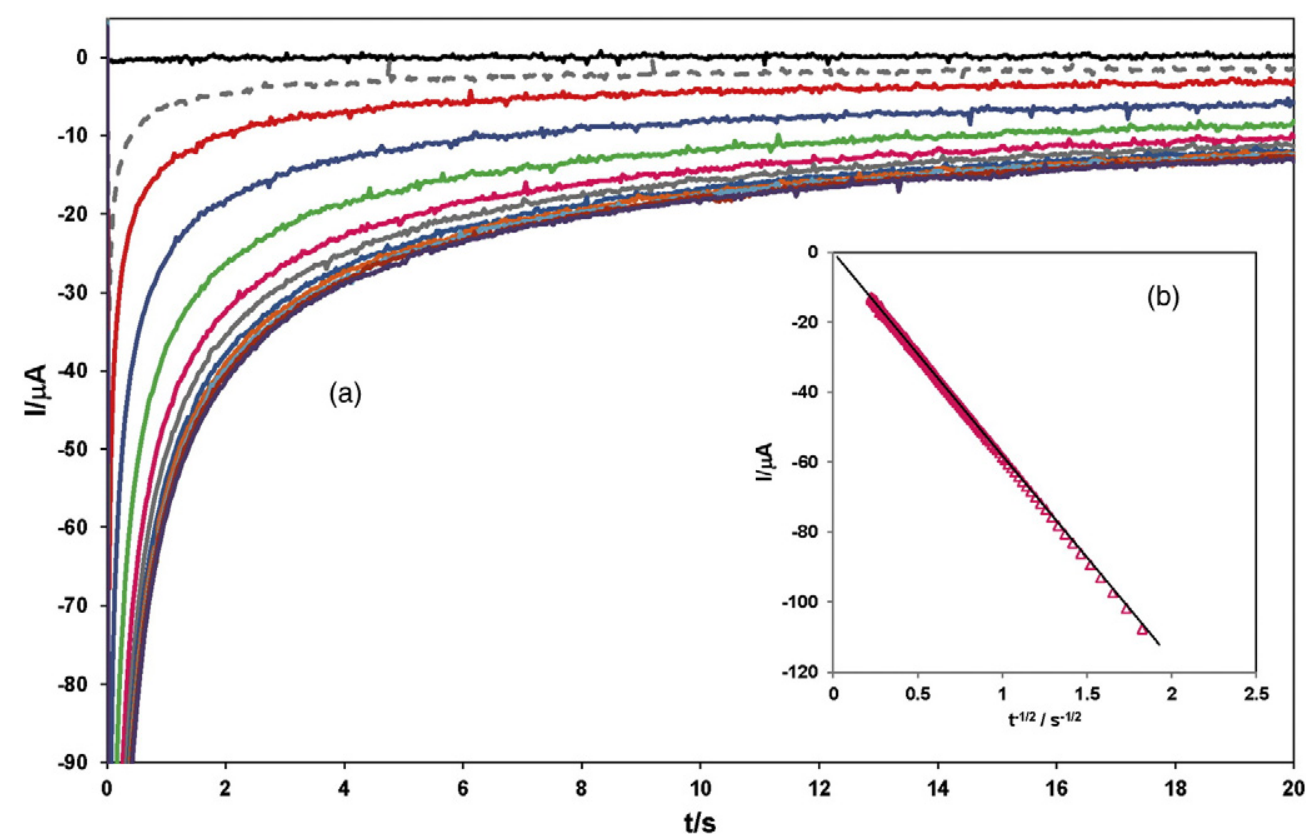

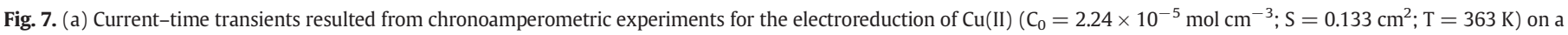

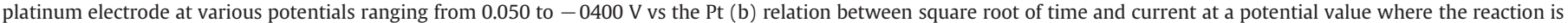
diffusion controlled.

Plots of $\ln D$ vs. $T / \eta$ can be made to check the fractional StokesEinstein relation in the following equation:

$\mathrm{D} \infty(T / \eta)^{\mathrm{m}}$

Good linearity was found with correlation coefficients $>98 \%$. The slopes of these lines, i.e. the exponent $\mathrm{m}$ was 0.98 .

\subsubsection{Evaluation of the kinetic parameters relative to the electrochemical} system $\mathrm{Cu}(\mathrm{II}) / \mathrm{Cu}(\mathrm{I})$

According to the previous results, the oxidation of $\mathrm{Cu}(\mathrm{I})$ or the reduction of $\mathrm{Cu}(\mathrm{II})$ at the interface of the Pt electrode, involves a diffusion step of the respective electroactive species $\mathrm{Cu}(\mathrm{I})$ or $\mathrm{Cu}(\mathrm{II})$ from the bulk solution to the electrode, a one-electron transfer step characterized by the intrinsic rate constant, $\mathrm{k}^{0}$, and the charge transfer coefficient, $\alpha$, and a second diffusion step corresponding to the electrogenerated species, $\mathrm{Cu}(\mathrm{II})$ or $\mathrm{Cu}(\mathrm{I})$, from the electrode surface to the bulk.

The kinetic parameters $\mathrm{k}^{0}$ and $\alpha$ can be obtained in practice: $\mathrm{i}$ ) by simulation of the cyclic voltammograms, and ii) from the analysis of the convoluted curves.

3.2.2.1. Determination of the charge transfer kinetic parameters by simulation of the cyclic voltammograms. The voltammograms were very reproducible, therefore the information of interest could be easily extracted from the comparison of the experimental curves and the simulated voltammograms calculated using a simulation computer program (M271 COOL kinetic analysis software 1.10). The simulation method is based upon a non-linear simplex optimization of the parameters in a

Table 2

Two-way analysis of variance (ANOVA) of the data reported on Table 1.

\begin{tabular}{|c|c|c|c|c|c|}
\hline \multicolumn{3}{|l|}{$\underline{\mathrm{D}_{\mathrm{Cu}(\mathrm{I})}}$} & \multicolumn{3}{|l|}{$\underline{\mathrm{D}_{\mathrm{Cu}(\mathrm{II})}}$} \\
\hline Factor & $\mathrm{F}_{\text {calculated }}$ & $\mathrm{F}_{\text {critical }}$ & Factor & $\mathrm{F}_{\text {calculated }}$ & $\mathrm{F}_{\text {critical }}$ \\
\hline Temperature & 78.8 & 3.86 & Temperature & 516.8 & 10.13 \\
\hline Technique & 3.72 & 3.86 & Technique & 6.01 & 9.28 \\
\hline \multicolumn{3}{|c|}{$\mathrm{D}_{\mathrm{Cu}(\mathrm{I})}$ and $\mathrm{D}_{\mathrm{Cu}(\mathrm{II})}$ at $343 \mathrm{~K}$} & \multicolumn{3}{|c|}{$\mathrm{D}_{\mathrm{Cu}(\mathrm{I})}$ and $\mathrm{D}_{\mathrm{Cu}(\mathrm{II})}$ at $363 \mathrm{~K}$} \\
\hline $\mathrm{D}_{\mathrm{Cu}(\mathrm{I})}$ and $\mathrm{D}_{\mathrm{Cu}(\mathrm{II})}$ & 3.80 & 10.13 & $\mathrm{D}_{\mathrm{Cu}(\mathrm{I})}$ and $\mathrm{D}_{\mathrm{Cu}(\mathrm{II})}$ & 1.54 & 10.13 \\
\hline Technique & 0.46 & 9.28 & Technique & 0.20 & 9.28 \\
\hline
\end{tabular}

normalized space derived from linear regression of the measured current on a calculated dimensionless current function, $\psi$, [32-34].

For quasi-reversible charge transfer the dimensionless current, $\psi$, is a well-known function of the kinetic parameters $\left(\alpha, \kappa, \mathrm{E}_{1 / 2}^{\mathrm{r}}\right)$, where $\alpha$ is the charge-transfer coefficient, $\mathrm{E}_{1 / 2}^{\mathrm{r}}$ the reversible half-wave potential (V), and kappa $\kappa$, that is defined by means of Eq. (11)

$\kappa=\frac{\mathrm{k}^{0}}{\mathrm{D}_{\mathrm{Cu}(\mathrm{II})}^{(1-\alpha) / 2} \mathrm{D}_{\mathrm{Cu}(\mathrm{I})}^{\alpha / 2}}$

being $\mathrm{k}^{0}$ the apparent standard rate constant $\left(\mathrm{cm} \mathrm{s}^{-1}\right), \mathrm{D}_{\mathrm{Cu}(\mathrm{II})}$ and $\mathrm{D}_{\mathrm{Cu}(\mathrm{I})}$ the diffusion coefficients $\left(\mathrm{cm}^{2} \mathrm{~s}^{-1}\right)$.

As it was expected from the previous diagnostic criteria, for low scan rates a good fit with the experimental voltammograms was achieved for a reversible model, whereas the best fits were found for a quasireversible process for scan rate values higher than $150 \mathrm{mV} \mathrm{s}^{-1}$. Representative examples of this simulation are shown in Fig. 9(a-b) and the average values obtained are gathered in Table 3.

On the other hand, the reversible half wave potential, $\mathrm{E}_{1 / 2}^{\mathrm{r}}$, obtained following this methodology, can be used for calculating the apparent standard potential, $\mathrm{E}^{0}$, of the electrochemical system $\mathrm{Cu}(\mathrm{II}) / \mathrm{Cu}(\mathrm{I})$ by using the following equation $[20,22,23,26]$ :

$\mathrm{E}_{1 / 2}^{\mathrm{r}}=\mathrm{E}_{0}^{0}+\frac{\mathrm{RT}}{\mathrm{F}} \ln \frac{\mathrm{D}_{\mathrm{Cu}(\mathrm{I})}^{1 / 2}}{\mathrm{D}_{\mathrm{Cu}(\mathrm{II})}^{1 / 2}}$

3.2.2.2. Determination of the charge transfer kinetic parameters from the analysis of the convoluted curves. As an alternative approach to the estimation of the kinetic parameters, an analysis of the convoluted curves was carried out. Goto and Oldham [35] and Myland and Oldham [36] have derived linear plots of logarithmic functions of convoluted current as a function of $\mathrm{E}$ for a quasi-reversible process.

The derived equation for a quasi-reversible reduction process is [35]:

$\mathrm{E}=\mathrm{E}_{1 / 2}^{\mathrm{r}}+\frac{2.3 \mathrm{RT}}{\alpha \mathrm{F}} \log \frac{\mathrm{k}^{0}}{\mathrm{D}^{1 / 2}}+\frac{2.3 \mathrm{RT}}{\alpha \mathrm{F}} \log B^{\prime}$ 


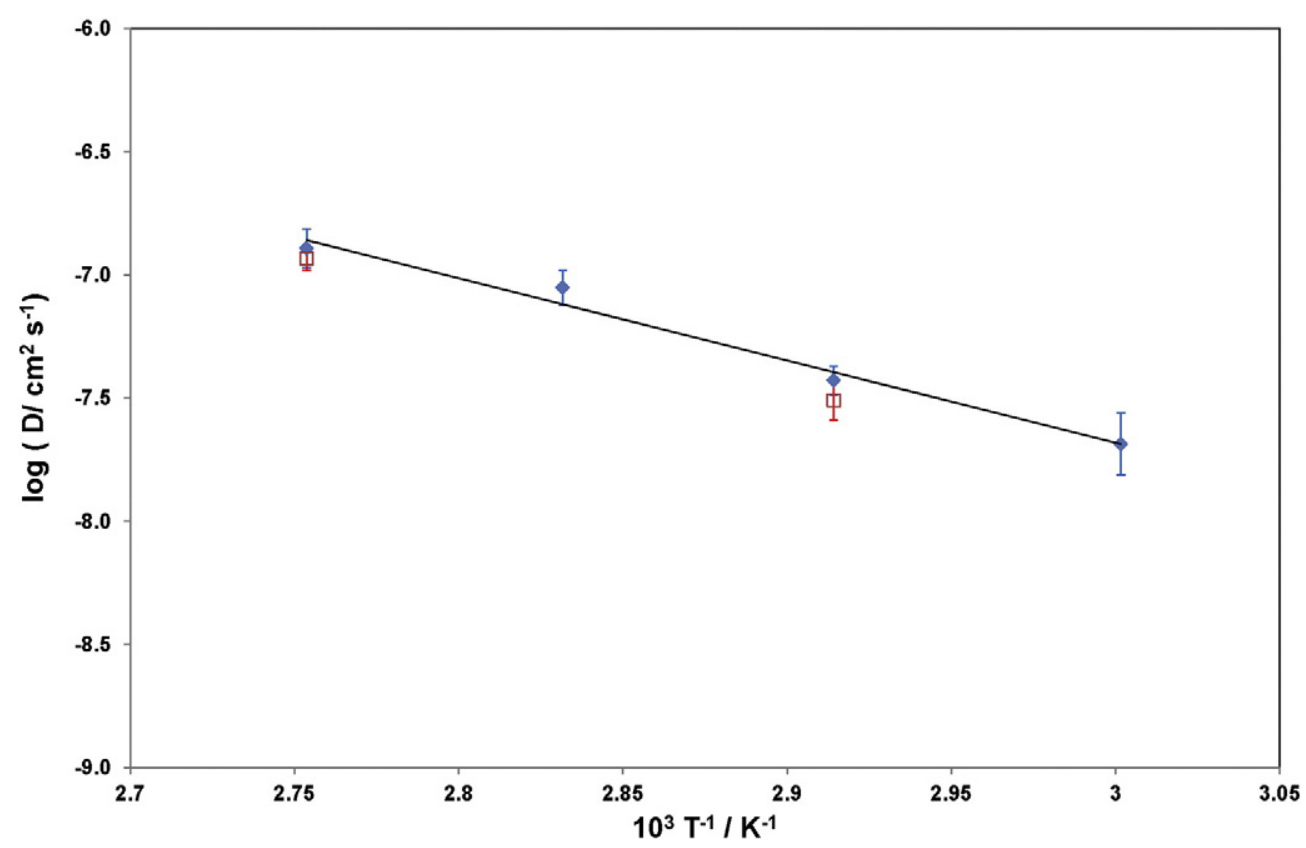

Fig. 8. Variation of the diffusion coefficients of $\mathrm{Cu}(\mathrm{II})(\square)$ and $\mathrm{Cu}(\mathrm{I})(\diamond)$ with temperature. Verification of Arrhenius's law.

where

$B^{\prime}=\left[\frac{\mathrm{m}^{*}-\mathrm{m}-\mathrm{m} \exp \left\{\frac{\mathrm{F}}{\mathrm{RT}}\left(\mathrm{E}-\mathrm{E}_{1 / 2}^{\mathrm{r}}\right)\right\}}{I}\right]$.

Whereas, for a quasi-reversible oxidation process the derived equation is [36]

$\mathrm{E}=\mathrm{E}_{1 / 2}^{\mathrm{r}}+\frac{2.3 \mathrm{RT}}{(1-\alpha) \mathrm{nF}} \log \frac{\mathrm{D}^{1 / 2}}{\mathrm{k}^{0}}+\frac{2.3 \mathrm{RT}}{(1-\alpha) \mathrm{nF}} \log B$

with

$B=\left[\frac{I}{\mathrm{~m}^{*}-\mathrm{m}-\mathrm{m} \exp \left\{\frac{\mathrm{nF}}{\mathrm{RT}}\left(\mathrm{E}_{1 / 2}^{\mathrm{r}}-\mathrm{E}\right)\right\}}\right]$

In these equations, $\mathrm{m}$ is the convoluted current, $\mathrm{m}^{*}$ its limiting value and I the intensity in the cyclic voltammograms. An example of the logarithmic analysis is shown in Fig. 10.

The average values of $\mathrm{k}^{0}$ and $\alpha$ obtained from the plot of the potential versus the logarithmic function of convoluted current, using the diffusion coefficients values obtained before, are summarized in Table 3 , being possible to see the agreement between the different calculating methods employed. According to Matsuda and Ayabe's criteria [37], the exchange $\mathrm{Cu}(\mathrm{II}) / \mathrm{Cu}(\mathrm{I})$ can be qualified as quasi-reversible on a $\mathrm{Pt}$ electrode at the three studied temperatures.

\subsection{Electrochemical system $\mathrm{Cu}(\mathrm{I}) / \mathrm{Cu}(0)$}

3.3.1. Apparent standard potential of the electrochemical system $\mathrm{Cu}(\mathrm{I}) / \mathrm{Cu}(0)$. Equilibrium constant of the comproportionation reaction

The apparent standard potential of the electrochemical system $\mathrm{Cu}(\mathrm{I}) / \mathrm{Cu}(0)$, was obtained by potentiometry, measuring the equilibrium potential of a copper wire immersed in a solution containing $\mathrm{Cu}$ (I) $2.24 \times 10^{-2} \mathrm{~mol} \mathrm{Kg}{ }^{-1}$, by means of the Nernst equation:

$\mathrm{E}_{\mathrm{eq}}=\mathrm{E}_{0(\mathrm{Cu}(\mathrm{I}) / \mathrm{Cu}(0))}^{\mathrm{app}}+2.3 \frac{\mathrm{RT}}{\mathrm{F}} \log [\mathrm{Cu}(\mathrm{I})]$

The obtained results are gathered in Table 4.

Furthermore, the equilibrium constant associated to the comproportionation reaction:

$\mathrm{Cu}(\mathrm{II})+\mathrm{Cu}(0) \rightleftharpoons 2 \mathrm{Cu}(\mathrm{I})$

can be calculated from the apparent standard potentials of the systems $\mathrm{Cu}(\mathrm{II}) / \mathrm{Cu}(\mathrm{I})$ and $\mathrm{Cu}(\mathrm{I}) / \mathrm{Cu}(0)$ by means of the following equation:

$\log \mathrm{k}=\frac{\mathrm{F}}{2.3 \mathrm{RT}}\left(\mathrm{E}_{0(\mathrm{Cu}(\mathrm{II}) / \mathrm{Cu}(\mathrm{I}))}^{\mathrm{app}}-\mathrm{E}_{0(\mathrm{Cu}(\mathrm{I}) / \mathrm{Cu}(0))}^{\mathrm{app}}\right)$

the obtained values, gathered on Table 4, show that $\mathrm{Cu}$ (II) can be completely reduced to $\mathrm{Cu}(\mathrm{I})$ by copper metal. A similar behavior has been reported by Vainikka et al. [14] in the 1-butyl-1methylpyrrolidinium bis(trifluoromethylsulfonyl)imide with 1-butyl-1methylpyrrolidinium chloride.

\subsubsection{Electrochemical study of copper deposition}

The experimental voltammograms suggest the presence of a nucleation phenomenon (Fig. 11), but mainly in a qualitative way. The electrodeposition of copper does not commence until a potential well beyond $\mathrm{E}_{\mathrm{rev}}$ is reached, an important separation being observed between the cathodic and anodic. The reason for this behavior is that the formation of stable $\mathrm{Cu}$ nuclei on an inert surface requires a potential more negative than the reduction of $\mathrm{Cu}(\mathrm{I})$ on a $\mathrm{Cu}$ surface.

Chronoamperometry was chosen to study the nucleation/growth process of copper on a Pt wire and a Pt disc electrode. The experiments were conducted with a $\mathrm{Cu}(\mathrm{I})$ solution, by stepping the potential from a value where no reaction of copper deposition takes place to those potentials sufficiently negative to initiate the nucleation/growth process (i.e. more cathodic than $-1.175 \mathrm{~V}$ ). To obtain accurate measurements and repeatable and reliable results, the structure and size of the electrode surface as well as the diffusion layer must be renewed before 
(a)

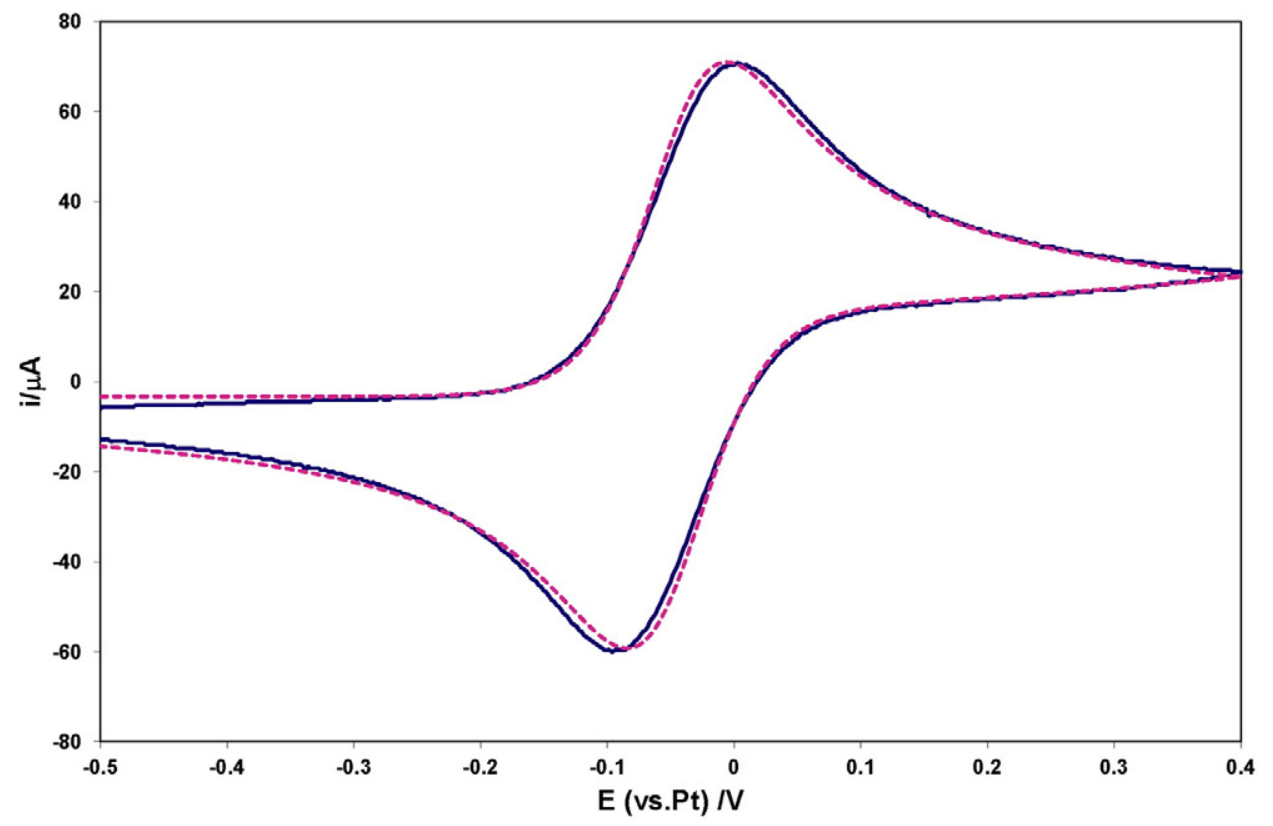

(b)

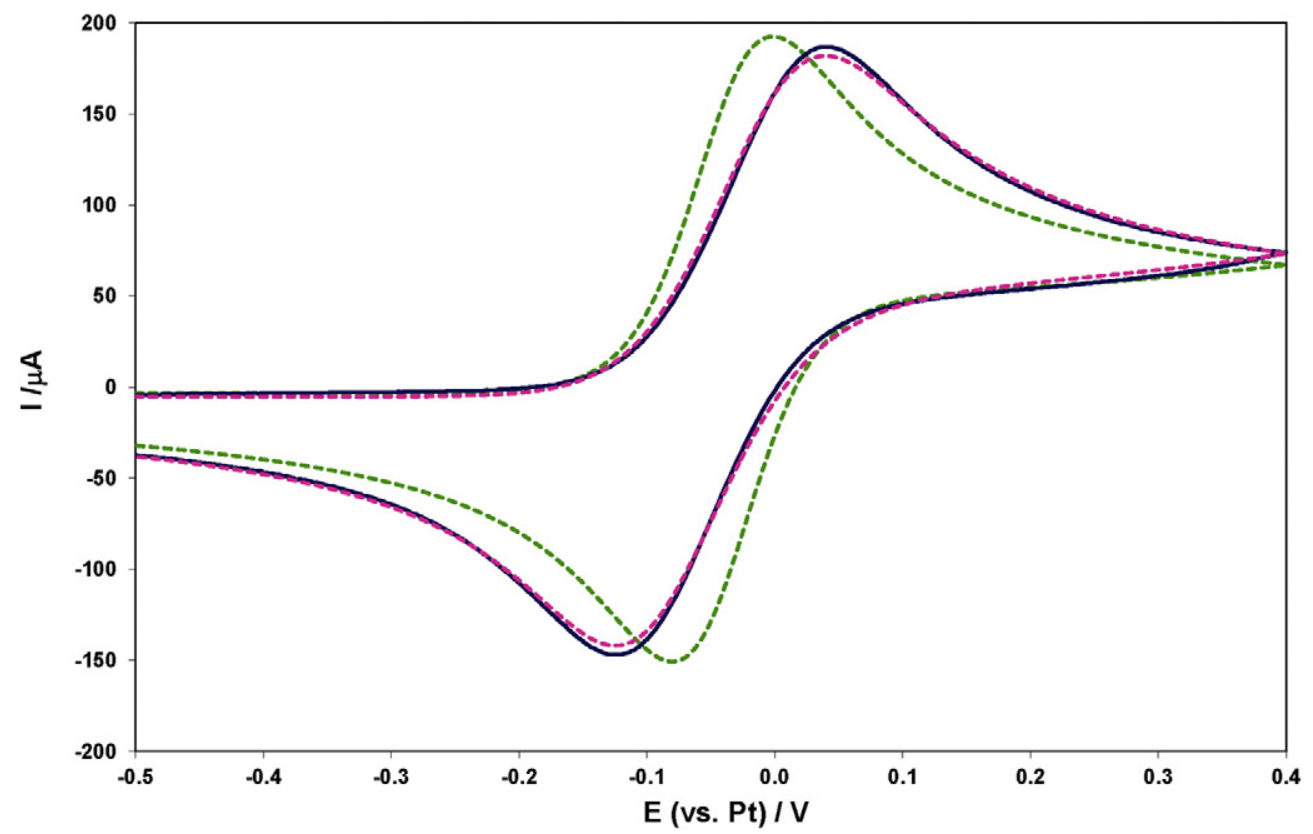

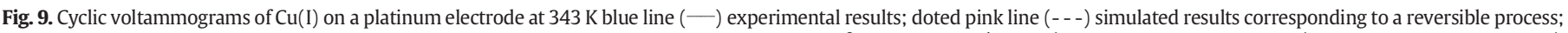

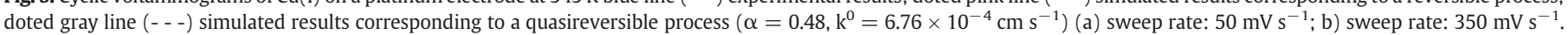
(For interpretation of the references to colour in this figure legend, the reader is referred to the web version of this article.)

Table 3

Kinetic parameters of $\mathrm{Cu}(\mathrm{II}) / \mathrm{Cu}(\mathrm{I})$ exchange in the $\mathrm{BMIMCl}$ obtained by different methods.

\begin{tabular}{|c|c|c|c|c|}
\hline Technique & $\mathrm{T} / \mathrm{K}$ & $\begin{array}{l}\mathrm{E}_{1 / 2}-\mathrm{vs} \\
\mathrm{Pt} / \mathrm{mV}\end{array}$ & $\alpha$ & $\log \mathrm{k}^{0} / \mathrm{cm} \mathrm{s}^{-1}$ \\
\hline \multirow{4}{*}{$\begin{array}{l}\text { CV(Kinetic analysis software, } \\
\text { COOL algorithm) }\end{array}$} & 333 & $-70 \pm 3$ & $0.46 \pm 0.04$ & $-3.71 \pm 0.05$ \\
\hline & 343 & $-51 \pm 1$ & $0.48 \pm 0.02$ & $-3.17 \pm 0.02$ \\
\hline & 353 & $-44 \pm 1$ & $0.46 \pm 0.06$ & $-3.31 \pm 0.10$ \\
\hline & 363 & $-41 \pm 1$ & $0.48 \pm 0.03$ & $-3.32 \pm 0.11$ \\
\hline \multirow[t]{4}{*}{$\mathrm{CV}+\mathrm{CPSV}$} & 333 & & $0.56 \pm 0.05$ & $-3.77 \pm 0.10$ \\
\hline & 343 & & $0.58 \pm 0.05$ & $-3.55 \pm 0.02$ \\
\hline & 353 & & $0.56 \pm 0.03$ & $-3.54 \pm 0.02$ \\
\hline & 363 & & $0.50 \pm 0.05$ & $-3.35 \pm 0.03$ \\
\hline
\end{tabular}

each measurement in order to obtain the same electrode/electrolyte interface conditions at the beginning of each test. Therefore, after every run: i) the deposited metal was removed from the surface by polarizing the working electrode anodically at $-0.450 \mathrm{~V}$ for a controlled time (90s), and ii) the solution was stirred without applying any voltage (open circuit) for $20 \mathrm{~s}$, until initial conditions are restored.

Examples of current-time transients resulting for such experiments are shown in Fig. 12. These transients initially exhibited a sharp current spike due to charging of the electrode double layer after the potential step was applied. This was followed by a rising current due to the formation and subsequent growth of copper nuclei on the electrode surface. The current then passed through a broad maximum $\left(\mathrm{t}_{\mathrm{m}}, \mathrm{I}_{\mathrm{m}}\right)$ and finally 


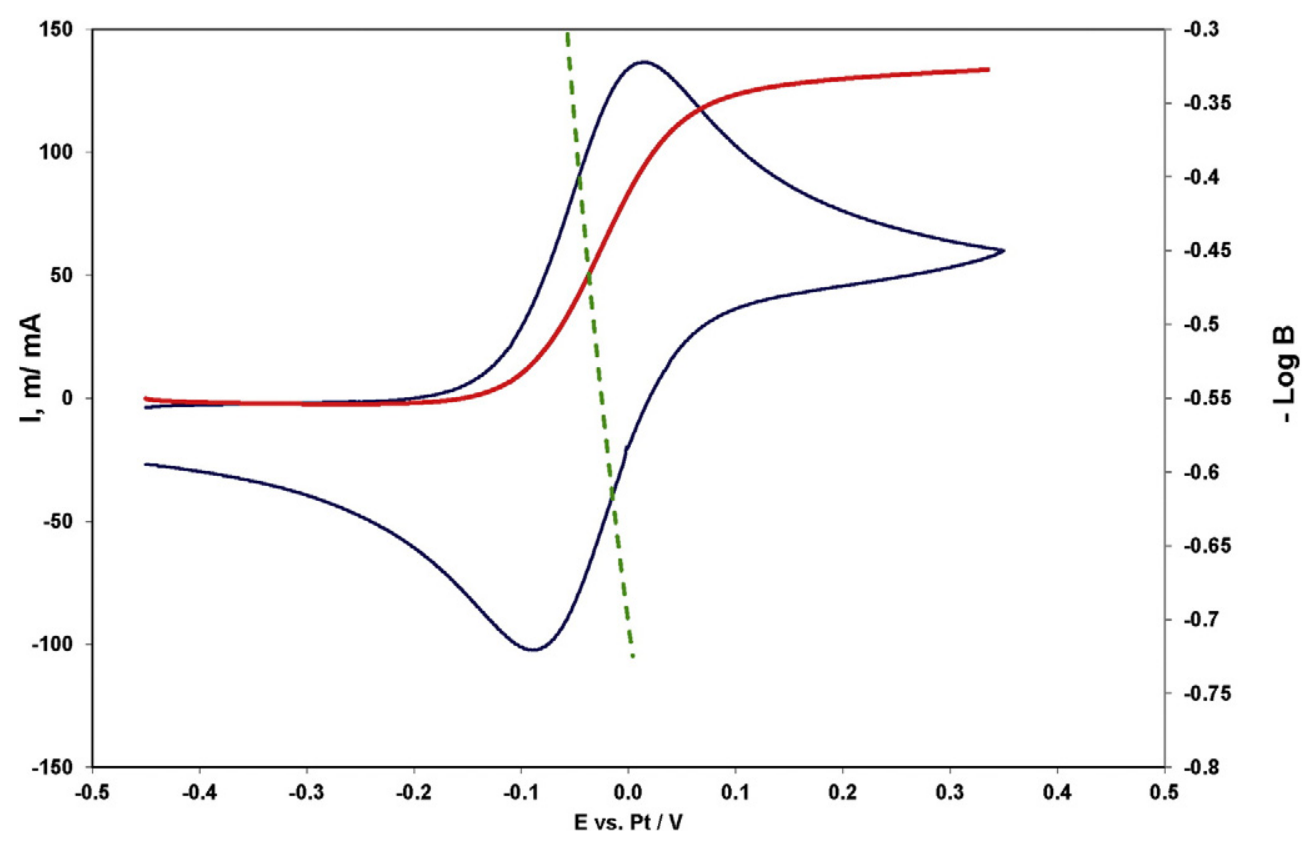

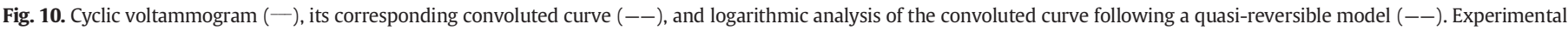
conditions: $\mathrm{Cu}(\mathrm{I})$ solution on a Pt wire electrode $\left(\mathrm{C}_{\mathrm{o}}=2.60 \times 10^{-5} \mathrm{~mol} \mathrm{~cm}^{-3}, \mathrm{~T}=353 \mathrm{~K}\right.$, scan rate $\left.0.200 \mathrm{~V} \mathrm{~s}^{-1}\right)$.

decreased with a linear I vs $\mathrm{t}^{-1 / 2}$ relation displaying diffusioncontrolled process. The time necessary to reach current maximum, $\mathrm{t}_{\mathrm{m}}$, depends on the overpotential, and decreases as the potential is made more negative.

In order to identify the copper nucleation mode, the dimensionless experimental current-time transients obtained at different applied cathodic potentials were compared with the dimensionless theoretical transient models derived by Scharifker and Hills [38]. The models utilize the coordinates of the chronoamperometric peaks in order to distinguish between the two limiting nucleation mechanisms: instantaneous and progressive, and are represented by Eqs. (20) and (21) respectively:

$\left(\frac{\mathrm{i}}{\mathrm{i}_{\mathrm{m}}}\right)^{2}=1.9542 \frac{\left[1-\exp \left(-1.2564\left(\mathrm{t} / \mathrm{t}_{\mathrm{m}}\right)\right)\right]^{2}}{\left(\mathrm{t} / \mathrm{t}_{\mathrm{m}}\right)}$

$\left(\frac{\mathrm{i}}{\mathrm{i}_{\mathrm{m}}}\right)^{2}=1.2254 \frac{\left[1-\exp \left(-2.3367\left(\mathrm{t} / \mathrm{t}_{\mathrm{m}}\right)^{2}\right)\right]^{2}}{\left(\mathrm{t} / \mathrm{t}_{\mathrm{m}}\right)}$

Instantaneous nucleation corresponds to immediate activation of all nucleation sites, where the rate of further nuclei formation is negligible in the time frame of the experiments. On the contrary, during progressive nucleation, the rate of new nuclei formation in the time frame of the experiment is not negligible.

In Fig. 13 the dimensionless experimental data, extracted from the chronoamperometric curves, are represented together with the theoretical curves for instantaneous and progressive nucleation at different temperatures. According to the figure is apparent that the initial stages of electrochemical deposition of copper on both platinum electrodes in the BMIMCl can be explained in terms of a model involving instantaneous nucleation with three-dimensional growth of the nuclei. The experimental data always fits the model in the 343-363 K

Table 4

Redox potentials for $\mathrm{Cu}(\mathrm{II}) / \mathrm{Cu}(\mathrm{I})$ and $\mathrm{Cu}(\mathrm{I}) / \mathrm{Cu}(0)$ in $\mathrm{BMIMCl} /(\mathrm{V}$ versus Pt, molal scale).

\begin{tabular}{llll}
\hline $\mathrm{T} / \mathrm{K}$ & $\mathrm{E}_{\mathrm{o}(\mathrm{Cu}(\mathrm{I}) / \mathrm{Cu}(0) / \mathrm{V}}^{\mathrm{app}}$ & $\mathrm{E}_{\mathrm{o}(\mathrm{Cu}(\mathrm{I}) / \mathrm{Cu}(0) / \mathrm{V}}^{\mathrm{app}}$ & $\mathrm{k}_{\mathrm{c}}=\frac{[\mathrm{Cu}(\mathrm{I})]^{2}}{[\mathrm{Cu}(\mathrm{II})]}$ \\
\hline 343 & $-0.836 \pm 0.05$ & $-0.051 \pm 0.001$ & $(3.4 \pm 0.7) \times 10^{11}$ \\
353 & $-0.841 \pm 0.03$ & $-0.044 \pm 0.001$ & $(2.4 \pm 0.8) \times 10^{11}$ \\
363 & $-0.845 \pm 0.04$ & $-0.041 \pm 0.001$ & $(1.4 \pm 0.4) \times 10^{11}$ \\
\hline
\end{tabular}

temperature range, indicating that the nucleation mode of copper is not influenced by temperature in this range.

\subsubsection{Potentiostatic electrolysis}

Based on the previous results, potentiostatic electrolysis were conducted for SEM EDX analysis on Pt wires (0.5 and $1.5 \mathrm{~mm}$ diameter) electrodes from the $\mathrm{BMIMCl}$ containing $\mathrm{Cu}(\mathrm{I})$. The plating solution was stirred by bubbling dried $\mathrm{N}_{2}$ during the experiments. After the electrolysis, the deposits were washed with water. All the deposits obtained were red brown in appearance with good adhesion (i.e. the material remained on the electrode surface after rinsing in an ultrasonic bath).

The microstructure of the films deposited at the Pt electrodes is shown in Fig. 14. The films were homogeneous and continuous for all the deposition parameters tested, and free of oxygen. They consisted of particles nearly hemispherical in shape, with the following characteristics: Median $=55.05 \mathrm{~nm}$, first quartile $\mathrm{Q}_{1}=44.37 \mathrm{~nm}$, third quartile $\mathrm{Q}_{3}=84.27 \mathrm{~nm}$.

\section{Conclusions}

The electrochemical behavior of $\mathrm{Cu}(\mathrm{II})$ and $\mathrm{Cu}(\mathrm{I})$ solutions in the ionic liquid 1-buthyl-3-methylimidazolium chloride, BMIMCl on $\mathrm{Pt}$ electrodes, has been investigated in the temperature range 343-363 K. Experiments performed in a controlled $\mathrm{N}_{2}$ atmosphere cell show that $\mathrm{Cu}(\mathrm{I})$ can be oxidized to $\mathrm{Cu}(\mathrm{II})$ and reduced to $\mathrm{Cu}(0)$, due to the stabilization of $\mathrm{Cu}^{+}$by chloride complexation, with only one predominant chlorocomplex, $\mathrm{CuCl}_{\mathrm{p}}^{1-\mathrm{p}}$, probably $\mathrm{CuCl}_{3}^{2-}$. The standard potential of the redox couples $\mathrm{Cu}(\mathrm{II}) / \mathrm{Cu}(\mathrm{I})$ and $\mathrm{Cu}(\mathrm{I}) / \mathrm{Cu}(0)$ have been respectively determined by simulation of the cyclic voltammograms and potentiometry, showing that $\mathrm{Cu}$ (II) ions can be reduced to $\mathrm{Cu}$ (I) by the copper metal according to the comproportionation reaction:

$$
\mathrm{Cu}(\mathrm{II})+\mathrm{Cu}(0) \rightleftharpoons 2 \mathrm{Cu}(\mathrm{I})
$$

whose constant has been calculated at three temperatures.

By combining different electrochemical techniques (i.e. cyclic voltammetry, convolutive potential sweep voltammetry, chronopotentiometry and chronoamperometry), it has been possible to determine the kinetic parameters characterizing the mass and the charge transfers related to the electrochemical system $\mathrm{Cu}(\mathrm{II}) / \mathrm{Cu}(\mathrm{I})$. 


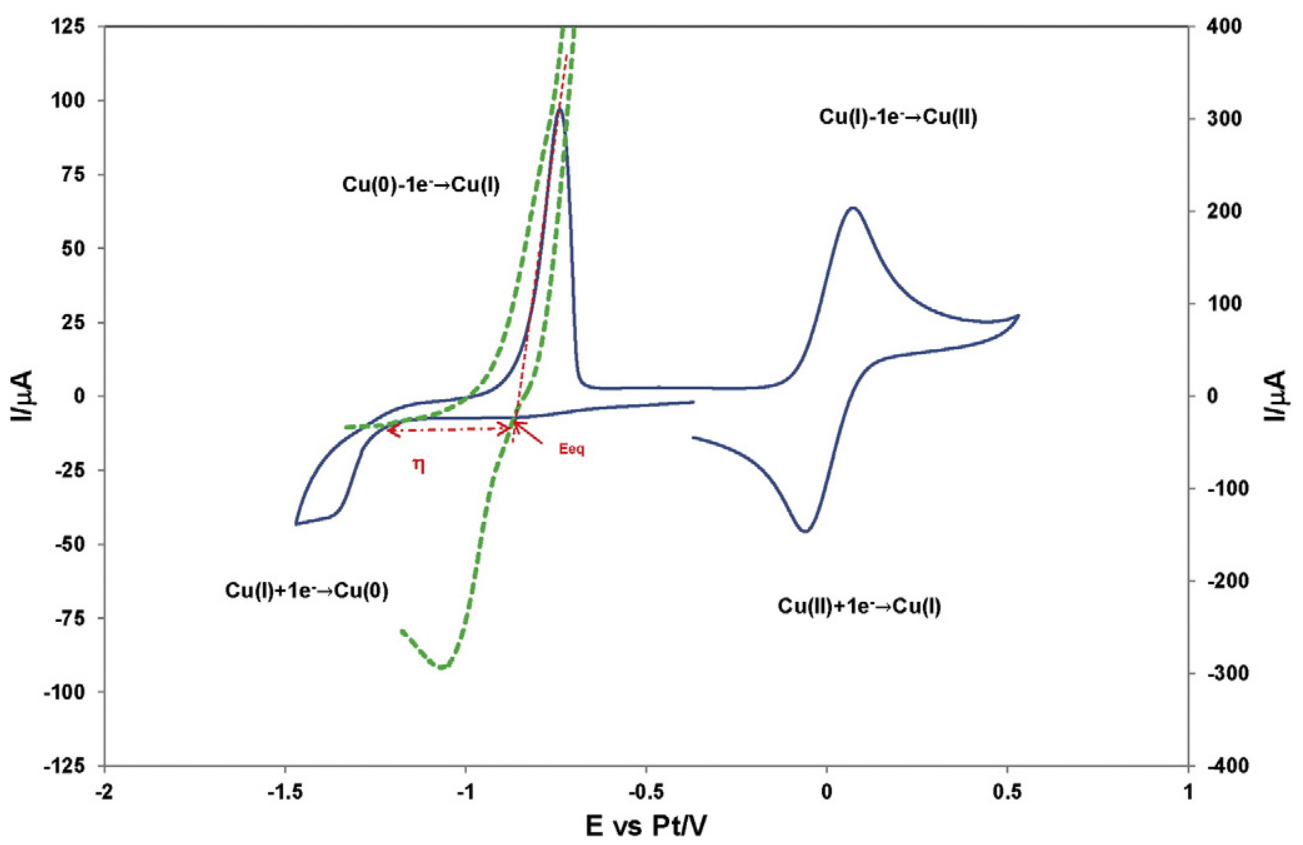

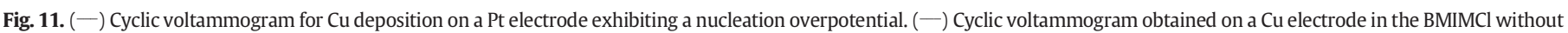
$\mathrm{Cu}(\mathrm{I})$.

The diffusion coefficient of $\mathrm{Cu}(\mathrm{I})$ and $\mathrm{Cu}(\mathrm{II})$ species were calculated using the mentioned electrochemical techniques using a Pt wire electrode. The statistical treatment of the data, a two-way analysis of variance (ANOVA), showed that with a 95\% confidence level, (i) all the methods used for the evaluation of the diffusion coefficients lead to the same value, and (iii) there are no significant differences between the diffusion coefficients of $\mathrm{Cu}(\mathrm{II})$ and $\mathrm{Cu}(\mathrm{I})$ in the interval of the studied temperatures.

The results pointed out the effect of the solvent viscosity on the diffusion coefficient of the electroactive species. In order to take into account this effect, the dimensionless Schmidt number $(\mathrm{Sc}=v / \mathrm{D})$ were calculated to characterize the solute global mass transport through its environment
On a Pt electrode, the electrochemical exchange $\mathrm{Cu}(\mathrm{II}) / \mathrm{Cu}(\mathrm{I})$ takes place in a quasi-reversible electrochemical mode. The intrinsic rate constant of charge transfer, $\mathrm{k}^{0}$, and the charge transfer coefficient, $\alpha$, have been calculated for the first time in the mentioned ionic liquid, by simulation of the cyclic voltammograms, logarithmic analysis of the convoluted curves and from the steady-state current potential curves.

On the other hand, nucleation and crystal growth plays an important role in the electrodeposition of metallic $\mathrm{Cu}$ onto the Pt surface. Experimental current-time transients followed the theoretical models based on instantaneous nucleation with three-dimensional growth of the nuclei at 343 and $363 \mathrm{~K}$. Electrodeposits of copper were obtained by potentiostatic electrolysis under $\mathrm{N}_{2}$ atmosphere and analyzed by

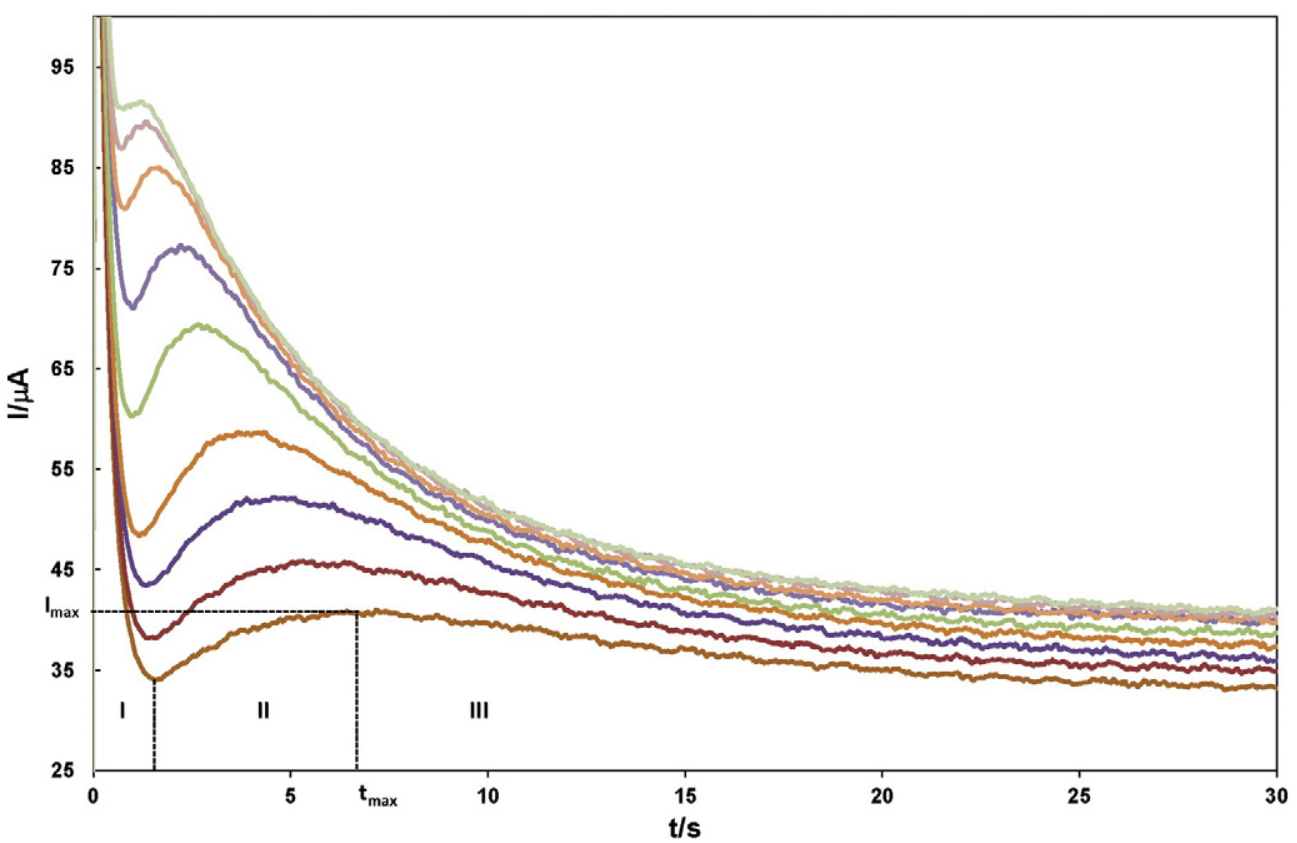

Fig. 12. Potentiostatic current-time transients of a $\mathrm{Cu}(\mathrm{I})$ solution $\left(\mathrm{C}_{0}=2.35 \times 10^{-5} \mathrm{~mol} \mathrm{~cm}^{-3}\right)$ on a Pt electrode (applied potentials from $-1.200 \mathrm{~V}$ to $\left.-1.375 \mathrm{~V}\right)$. 


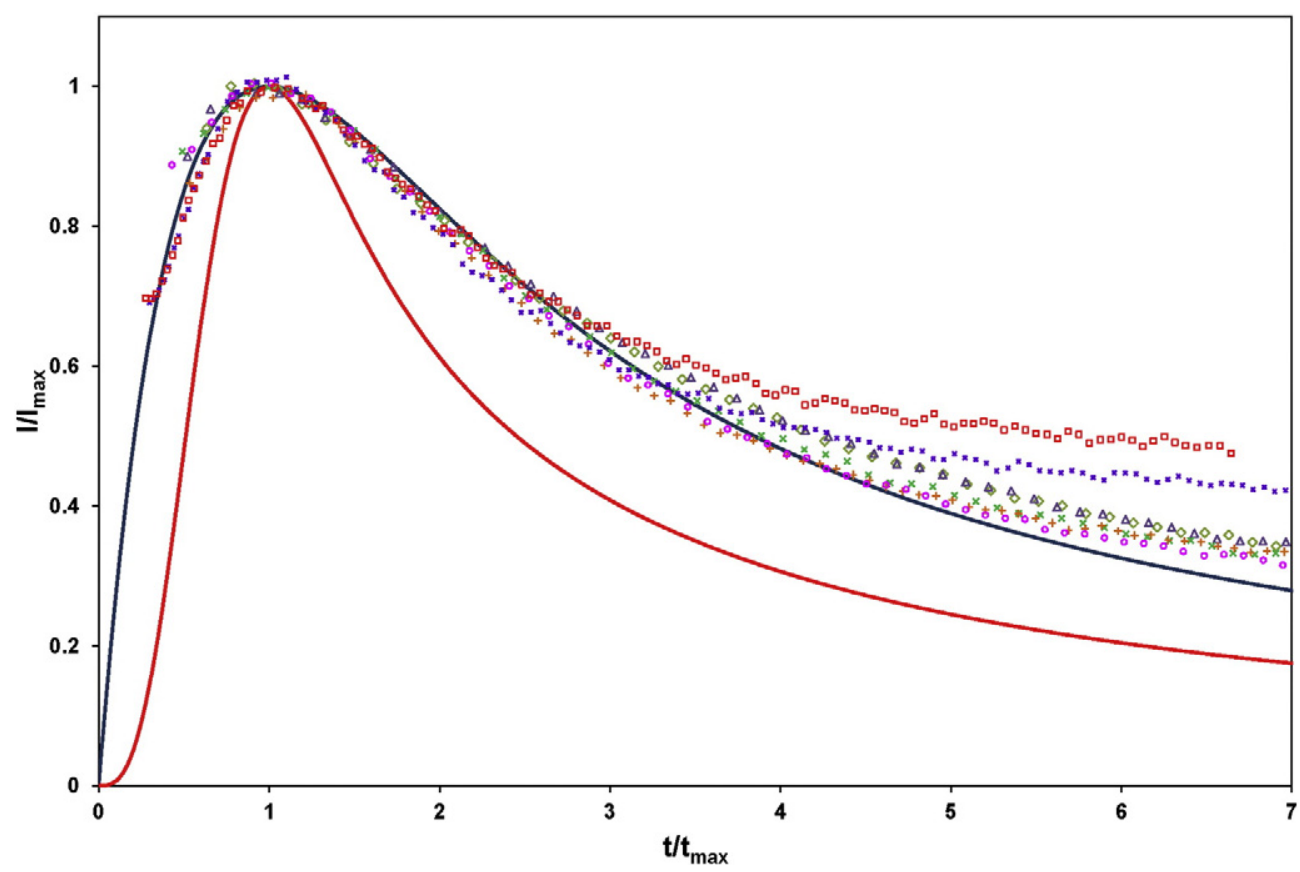

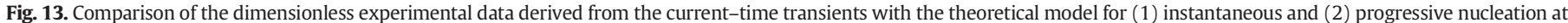
different working potentials on a Pt wire (from -1.225 to $-1.375 \mathrm{~V}$ ).

scanning electron microscopy with EDAX. They consisted of particles nearly hemispherical in shape, being the median $=55,05 \mathrm{~nm}, \mathrm{Q}_{1}=$ $44,37 \mathrm{~nm}$, and $\mathrm{Q}_{3}=84.27 \mathrm{~nm}$.

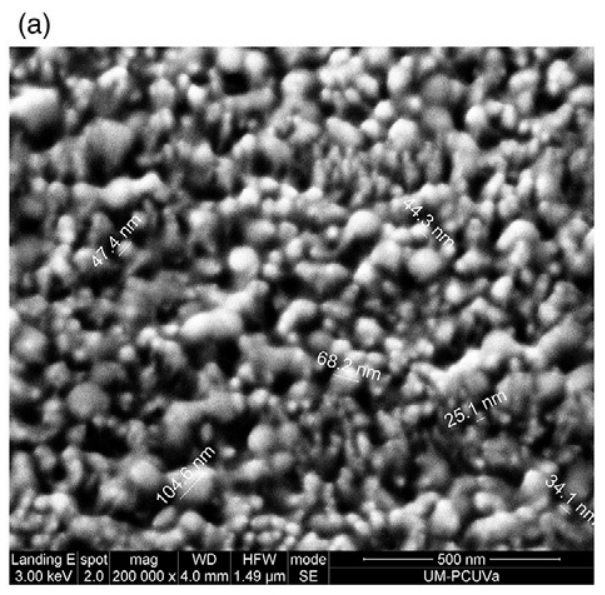

(b)

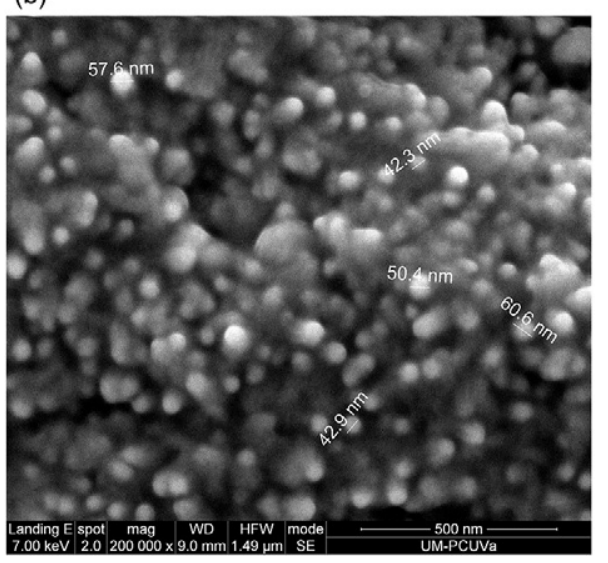

Fig. 14. SEM micrographs of copper electrodeposits: (a) Pt wire $0.5 \mathrm{~mm}$ diameter $\mathrm{E}_{\mathrm{d}}=-1.4 \mathrm{~V} \mathrm{t}_{\mathrm{d}}=3600 \mathrm{~s}$, (b) Pt wire $1.5 \mathrm{~mm}$ diameter, $\mathrm{E}_{\mathrm{d}}=-1.5 \mathrm{~V} \mathrm{t} \mathrm{t}_{\mathrm{d}}=3600 \mathrm{~s}$.

\section{Acknowledgements}

Authors thank the Junta de Castilla y León Project VA171U14 and the Ministerio de Ciencia e Innovación (Spain) Project CTQ2010-19912 for financial support.

\section{References}

[1] M.J. Earle, J.R. Seddon, Ionic liquids. Green solvents for the future, Pure Appl. Chem $72(2000) 1391$.

[2] K. Takao, T.J. Bell, Y. Ikeda, Actinide chemistry in ionic liquids, Inorg. Chem. 52 (2013) 3459

[3] Ch. Jagadeeswara Rao, K.A. Venkatesan, B.V.R. Tata, K. Nagarajan, T.G. Srinivasan, P.R. Vasudeva Rao, Radiation stability of some room temperature ionic liquids, Radiat. Phys. Chem. 80 (2011) 643

[4] Y. Castrillejo, C. Abejón, M. Vega, R. Pardo, E. Barrado, Chemical and electrochemical behaviour of copper ions in the $\mathrm{ZnCl}_{2}-2 \mathrm{NaCl}$ mixture at $450{ }^{\circ} \mathrm{C}$, Electrochim. Acta 42 (1997) 1495.

[5] Y. Castrillejo, M.R. Bermejo, A.M. Martínez, R. Pardo, S. Sánchez, G.S. Picard, Electrochemical behaviour of copper ions in molten equimolar $\mathrm{CaCl}_{2}-\mathrm{NaCl}$ mixture at $550{ }^{\circ} \mathrm{C}$. High Temp. Mater. Process. 3 (1999) 279.

[6] J. Vazquez-Arenas, G. Vázquez, A.M. Meléndez, I. González, The effect of the $\mathrm{Cu}^{2+}$ $\mathrm{Cu}^{+}$step on copper electrocrystallization in acid noncomplexing electrolytes, J. Electrochem. Soc. 154 (2007) D473.

[7] P. Sebastian, E. Torralba, E. Vallés, A. Molina, E. Gómez, Advances in copper electrodeposition in chloride excess. A theoretical and experimental approach, Electrochim. Acta 164 (2015) 187

[8] C. Nourry, L. Massot, P. Chamelot, P. Taxil, Electrochemical reduction of Gd(III) and $\mathrm{Nd}$ (III) on reactive cathode material in molten fluoride media, J. Appl. Electrochem. 39 (2009) 927.

[9] F. Qiao, A.C. West, The impact of cations on nucleous density during copper electrodeposition, Electrochim. Acta 150 (2014) 8

[10] P. Sebastián, E. Valles, E. Gómez, Copper electrodeposition in a deep eutectic solvent First stages analysis considering $\mathrm{Cu}(\mathrm{I})$ stabilization in chloride media, Electrochim. Acta 123 (2014) 285.

[11] P.Y. Chen, Y.T. Chang, Voltammetric study of copper in 1-butyl-3methylimidazolium salicylate ionic liquid, Electrochim. Acta 75 (2012) 339.

[12] P.Y. Chen, I.W. Sun, Electrochemical study of copper in a basic 1-ethyl-3 methylimidazolium tetrafluoroborate room temperature molten salt, Electrochim. Acta 45 (1999) 441.

[13] S.Z. El Abedin, A.Y. Saad, H.K. Farag, N. Borisenko, Q.X. Liu, F. Endres, Electrodeposition of selenium, indium and copper in an air-and water-stable ionic liquid at variable temperatures, Electrochim. Acta 52 (2007) 2746.

[14] T. Vainikka, D. Lloyd, L. Murtomäki, J.A. Manzanares, K. Kontturi, Electrochemica study of copper chloride complexes in the RTIL 1-butyl-1-methylpirrolidinium bis(trifluoromethylsulfonil)imide, Electrochim. Acta 87 (2013) 739.

[15] T.M. Laher, C.L. Hussey, Copper (I) and Cu(II) chlorocomplexes in the basic aluminum chloride-1-methyl-3-ethylimidazolium chloride ionic liquid, Inorg. Chem. 22 (1983) 3247. 
[16] D. Bermejo personal communication.

[17] R. Sescousse, Kim Anh Le, M.E. Ries, T. Budtova, Viscosity of cellulose-imidazoliumbased ionic liquid solutions, J. Phys. Chem. B 114 (2010) 7222

[18] A.A.J. Torriero, J. Sunarso, P.C. Howlett, Critical evaluation of reference system for voltammetric measurements in ionic liquids, Electrochim. Acta 82 (2012) 60.

[19] M. Galinski, A. Lewandowski, I. Stepniak, Ionic liquids as electrolytes, Electrochim. Acta 51 (2006) 5567.

[20] A.J. Bard, L.R. Faulkner, Electrochemical Methods: Fundamentals and Applications, Wiley, New York, 2001

[21] L. Ramalay, M.S. Krause, Theory of square wave voltammetry, Anal. Chem. 41 (11) (1969) 1363.

[22] Southampton Electrochemistry Group, Instrumental Methods in Analytical Chemistry, University of Southampton, Horwood, Chichester, 2001.

[23] Z. Galus, Fundamental of Electrochemical Analysis, second ed. Ellis Horwood, Chichester and Polish Scientific Publishers, Warsaw, 1994.

[24] D. Renaud, Doctoral Thesis, Grenoble, France, 1985

[25] J.C. Imbeaux, J.M. Savéant, Convolutive potential sweep voltammetry, J. Electroanal. Chem. 44 (1973) 169.

[26] D.D. Mc Donald, Transient Techniques in Electrochemistry, Plenum Press, New York, 1997.

[27] M. Jakakumar, K.A. Venkatesan, T.G. Srinivasan, Electrochemical behavior of fission palladium in 1-butyl-3-methylimidazolium chloride, Electrochim. Acta 52 (2007) 7121.
[28] P. Giridhar, K.A. Venkatesan, T.G. Srinivasan, P.R. Vasudeva Rao, Electrochemical behavior of uranium (VI) in 1-butyl-3-methylimidazolium chloride and thermal characterization of uranium oxide deposit, Electrochim. Acta 52 (2007) 3006.

[29] A. Mandroyan, M. Mourad-Mahmoud, M.L. Doche, J.Y. Hihn, Effects of ultrasound and temperature on copper electro reduction in deep eutectic solvents (DES), Ultrason. Sonochem. 21 (2014) 2010.

[30] D.M. Massart, B.G.M. Vandeginste, L.M.C. Buydens, S. de Jong, P.J. Lewi, J. SmeyersVerbeke, Handbook of Chemometrics and Qualimetrics, Elsevier, Amsterdam, 1997.

[31] Qiu-yue Zhang, Hui He, Xiao-hong Huang, Guo-an Ye, Electrochemical behavior of europium (III) in 1-butyl-3-methylimidazolium, J. Electrochem. 16 (2010) 79.

[32] J. O'Dea, J. Osteryoung, R. Osteryoung, Square wave voltammetry and other pulse techniques for the determination of kinetic parameters. The reduction of zinc(II) at mercury electrodes, J. Phys. Chem. 87 (1983) 3911.

[33] J. O'Dea, J. Osteryoung, T. Lane, Determining kinetic parameters from pulse voltammetric data, J. Phys. Chem. 90 (1986) 2761.

[34] J. Osteryoung, Voltammetry for the future, Acc. Chem. Res. 26 (1993) 77.

[35] M. Goto, K.B. Oldham, Semiintegral electroanalysis: shapes of neopolarograms, Anal. Chem. 45 (1973) 2043.

[36] J.C. Myland, K.B. Oldham, Quasireversible linear-potential-sweep voltammetry: an analytic solution for rational $\alpha$, Anal. Chem. 66 (1994) 1866.

[37] H. Matsuda, Y. Ayabe, Zur Theorie der Randles-Sevcikschen KathodenstrahlPolarographie, Z. Elektrochem. 59 (1955) 494

[38] F.B. Scharifker, G. Hills, Theoretical and experimental studies of multiple nucleation, Electrochim. Acta 28 (1983) 879. 